\title{
Endocrine
}

\section{Early post-natal life stress induces permanent adrenocorticotropin-dependent hypercortisolism in male mice

\author{
--Manuscript Draft--
}

\begin{tabular}{|c|c|}
\hline Manuscript Number: & ENDO-D-20-01561R1 \\
\hline Full Title: & $\begin{array}{l}\text { Early post-natal life stress induces permanent adrenocorticotropin-dependent } \\
\text { hypercortisolism in male mice }\end{array}$ \\
\hline Corresponding Author: & $\begin{array}{l}\text { Stefano Loizzo } \\
\text { National Institute of Health: Istituto Superiore Di Sanita } \\
\text { ITALY }\end{array}$ \\
\hline \multicolumn{2}{|l|}{$\begin{array}{l}\text { Corresponding Author Secondary } \\
\text { Information: }\end{array}$} \\
\hline Corresponding Author's Institution: & National Institute of Health: Istituto Superiore Di Sanita \\
\hline \multicolumn{2}{|l|}{$\begin{array}{l}\text { Corresponding Author's Secondary } \\
\text { Institution: }\end{array}$} \\
\hline \multirow[t]{7}{*}{ Order of Authors: } & Gabriele Campana \\
\hline & Stefano Loizzo \\
\hline & Andrea Fortuna \\
\hline & Roberto Rimondini \\
\hline & Zaira Maroccia \\
\hline & Alfredo Scillitani \\
\hline & Alberto Falchetti \\
\hline \multicolumn{2}{|l|}{ Funding Information: } \\
\hline Abstract: & $\begin{array}{l}\text { Purpose It has been hypothesized that specific early-life stress (ES) procedures on } \\
\text { CD-1 male mice produce diabetes-like alterations due to the failure of negative } \\
\text { feedback of glucocorticoid hormone in the pituitary. The aim of this study is to } \\
\text { investigate the possible mechanism that leads to this pathological model, framing it in a } \\
\text { more specific clinical condition. } \\
\text { Methods Metabolic and HPA-related hormones of stressed mice (SM) have been } \\
\text { analyzed immediately after stress procedures ( } 21 \text { postnatal day, PND) and after } 70 \\
\text { days of a peaceful (unstressed) period (90PND). These data have been compared to } \\
\text { parameters from age-matched controls (CTR), and mice treated during ES procedures } \\
\text { with oligonucleotide antisense for pro-opiomelanocortin (AS-POMC). } \\
\text { Results At } 21 \text { PND, SM presented an increased exhibition of hypothalamic CRH and } \\
\text { pituitary POMC - derived peptides, as well as higher plasmatic levels of ACTH and } \\
\text { corticosterone vs CTR. At } 90 \mathrm{PND,} \mathrm{SM} \mathrm{showed} \mathrm{hyperglycemia,} \mathrm{with} \mathrm{also} \mathrm{suppression} \\
\text { of hypothalamic CRH, while pituitary and plasmatic ACTH levels, as well as plasma } \\
\text { corticosterone, were constantly higher than in CTR. These values are accompanied by } \\
\text { a progressive acceleration in gaining total body weight, which became significant } \\
\text { versus CTR at } 90 \text { PND. Treatment with AS-POMC prevented all hormonal and } \\
\text { metabolic alterations observed in SM, both at } 21 \text { and } 90 \mathrm{PND.}\end{array}$ \\
\hline
\end{tabular}


Conclusion These findings show that these specific ES procedures affect the negative glucocorticoid feedback in the pituitary, but not in the hypothalamus, suggesting a novel model of ACTH-dependent hypercortisolism that can be prevented by silencing the POMC gene.

\section{Response to Reviewers:}

Early post-natal life stress induces permanent adrenocorticotropin-dependent hypercortisolism in male mice

Endocrine

Dear Dr. Loizzo,

Your paper has now been carefully evaluated by an Associate Editor and ad hoc external Reviewers. We are sorry to say that it is not acceptable for publication in Endocrine in its present form. However, we would be ready to reconsider it if appropriately and extensively revised according to the enclosed comments. If you are prepared to undertake the work required we encourage you to resubmit your revised manuscript although at this stage no commitment can be made on our final decision.

Dear Editor,

We thank the Reviewer for their interest in our work. We did our best to respond to the point raised. As reported below, we have checked to the comment provided by the Reviewer and have made changes according to his indications.

\section{COMMENTS FOR THE AUTHOR:}

Reviewer \#1: The authors have demonstrated that the early-life stress can induce ACTH-dependent hypercortisolism after a 70 days unstressed period. This observation is a very interesting, and may be a clue for the elucidation of the etiology of Cushing's disease. I am very curious about the histology of mice pituitary histology. Can you show us the data of pituitary histology of PND and 90PND mice, since I wonder if the hypertrophy or tumorigenesis may occur at 90PND.

Answer: We completely agree with Referee \#1. Unfortunately, we have not available autoptic or perfused mice tissues, at the moment, but we have observed a slight but significant difference $(p=0.0291)$ in weights of fresh pituitary glands that were dissected from stressed mice $(20,6 \pm 2,1 \mathrm{mg})$ versus control mice $(30 \pm 2,8 \mathrm{mg})(\mathrm{n}=5)$ at the older age. This information has been added to the revised version of the manuscript at page 7, line 176 in the Results section and reported in a new Fig. 4. This result is discussed at page 9 , line $235-237$ in the Discussion section. 


\section{Early post-natal life stress induces permanent adrenocorticotropin-dependent 1 22 hypercortisolism in male mice}

Gabriele Campana $^{1}$ - Stefano Loizzo ${ }^{2}$ - Andrea Fortuna ${ }^{2}$ - Roberto Rimondini ${ }^{3}$ - Zaira Maroccia ${ }^{2}$. Alfredo Scillitani $^{4} \cdot$ Alberto Falchetti $^{5} \cdot$ Santi Mario Spampinato $^{1} \cdot$ Luca Persani $^{5,6} \S$ Iacopo Chiodini ${ }^{5,6} \S$

${ }^{1}$ Department of Pharmacy and Biotechnology, University of Bologna, Via Irnerio 48, 40126, Bologna, Italy

${ }^{2}$ Department of Cardiovascular and Endocrine-Metabolic Diseases and Aging, Istituto Superiore di Sanità, Viale Regina Elena 299, 00161, Rome, Italy

${ }^{3}$ Department of Medical and Clinical Sciences, University of Bologna, Via Irnerio 48, 40126, Bologna, Italy

${ }^{4}$ Endocrinology and Diabetology, Ospedale "Casa Sollievo della sofferenza" IRCCS, Viale Cappuccini 1, 71013, San Giovanni Rotondo, Foggia, Italy

${ }^{5}$ Department of Clinical Sciences and Community Health, University of Milan, Via della Commenda 19, 20122, Milan, Italy

${ }^{6}$ Division of Endocrine and Metabolic Diseases \& Lab. of Endocrine and Metabolic Research, IRCCS Istituto Auxologico Italiano, Piazzale Brescia 20, 20149 Milan, Italy.

$\S$ Equal author contribution

\section{Corresponding author: Stefano Loizzo}

E-mail: stefano.loizzo@iss.it

ORCID: 0000-0001-6344-2613

Key words: Cushing's syndrome · Pituitary ACTH hypersecretion · Metabolic syndrome $\cdot$ Early-life stress · Mouse.

Acknowledgments: Thanks are due to Alberto Loizzo for support and helpful comments that have improved our work, to Andrea Martinelli, Paolo Frassanito, and Flavio Torriani (ISS) for valuable animal care. 


\section{Abstract}

Purpose It has been hypothesized that specific early-life stress (ES) procedures on CD-1 male mice produce diabeteslike alterations due to the failure of negative feedback of glucocorticoid hormone in the pituitary. The aim of this study is to investigate the possible mechanism that leads to this pathological model, framing it in a more specific clinical 9 condition.

Methods Metabolic and HPA-related hormones of stressed mice (SM) have been analyzed immediately after stress procedures (21 postnatal day, PND) and after 70 days of a peaceful (unstressed) period (90PND). These data have been compared to parameters from age-matched controls (CTR), and mice treated during ES procedures with oligonucleotide antisense for pro-opiomelanocortin (AS-POMC).

Results At 21PND, SM presented an increased secretion of hypothalamic CRH and pituitary POMC-derived peptides, as well as higher plasmatic levels of ACTH and corticosterone vs CTR. At 90PND, SM showed hyperglycemia, with alse suppression of hypothalamic $C R H$, while pituitary and plasmatic $A C T H$ levels, as well as plasma corticosterone, were constantly higher than in CTR. These values are accompanied by a progressive acceleration in gaining total body weight, which became significant versus CTR at 90PND together with a higher pituitary weight. Treatment with ASPOMC prevented all hormonal and metabolic alterations observed in SM, both at 21 and 90PND.

Conclusion These findings show that these specific ES procedures affect the negative glucocorticoid feedback in the pituitary, but not in the hypothalamus, suggesting a novel model of ACTH-dependent hypercortisolism that can be prevented by silencing the $P O M C$ gene. 


\section{Introduction}

1

The hypothalamic-pituitary-adrenal (HPA) axis is a complex set of direct influences and feedback interactions among three components: the hypothalamus, the pituitary gland, and the adrenal glands [1,2]. Since HPA axis is a major neuroendocrine system, it is in charge of controlling the reactions to stress and regulates many body processes, including the immune system [3], mood and emotions [4], sexual desire regulation [5], and energy storage and consumption [2]. Thereby, an alteration of the HPA axis homeostasis can lead to behavioral disorders and metabolic diseases [6].

As it is known, the HPA axis has intrinsic plasticity in the early-life's phases in humans [7]. Indeed, this situation could explain much evidences and suggest that conditions of stress might alter the HPA axis activity, which leads consequently to glucocorticoids (GCs) hypersecretion [8]. In past times, it has already been proposed to maintain an occasional relationship between Cushing's syndrome (CS) and stress conditions throughout infancy $[9,10]$.

The condition of hypercortisolism provokes some of the hallmark signs as insulin resistance, dyslipidemia, vascular alterations, bone fragility, and body overweight [11-16]. Interestingly, these findings are similar to the phenotype of early-life stress (ES) mouse model developed in our laboratories [17-19]. Likewise other ES models [20,21], this mouse is submitted to complex ES procedures that could mimic the neonatal intensive care unit. After an unstressed period of 70 days, the mice present hyperglycemia, hyperinsulinemia, and body overweight, caused by a persisting GCs surplus $[17,22,23]$, which may be associated with an up-regulation of the negative GCs feedback mechanisms [19].

Thus, this mouse's pathology presents itself as a suitable model for clarifying the relationship between chronic stress in early-life and the related HPA axis activation, as a possible pathogenic cause of hypercortisolism.

To understand the early stress-related pathogenesis of this model, we have been analyzing the hypothalamus and pituitary expression, and circulating hormones at different ages (immediately after stress procedures and after 70 days under unstressed conditions). These results have been compared with those obtained as much in unstressed mice as in stressed mice, treated with antisense oligodeoxynucleotide versus pro-opiomelanocortin (AS-POMC, or AS).

\section{Material and methods}

\section{Ethics guidelines}

All the procedures were carried out in accordance with the guidelines of the Council of European Communities (European Communities Council Directive of 24 November 1986, 86/609/EEC) and following the approval of the Bioethical Committee of the Italian National Institute of Health (Istituto Superiore di Sanità - ISS), and the Italian Ministry of Health. All possible efforts have been made to minimize animal suffering and to reduce the number of 
animals used. For the current investigation, no alternatives to in vivo techniques are available. We confirm that all mandatory laboratory health and safety procedures have been complied throughout the course of any experimental work presented in this paper.

\section{Animal general procedures}

Pregnant multiparous outbred laboratory-born CD-1 mice were sent by the factory (Charles River Italia, Calco, Italy) and arrived at the $14^{\text {th }}$ day of conception age in the ISS vivarium; all mice were housed in single cages in a central facility and maintained under controlled conditions of $55 \pm 5 \%$ humidity and temperature of $21 \pm 1{ }^{\circ} \mathrm{C}$, in a photoperiod of 12 hours' light and dark, with the light turned on at 07:00. Mice were fed a standard $(6.55 \% \mathrm{kcal}$ from fat and 3.9 kcal/g; 4RF21, Mucedola, Italy) diet, food, and water are available ad libitum.

\section{Drugs}

AS-POMC was produced by EUROBIO Laboratories (Les Ulis Cedex, France). The 21-base sequence of AS-POMC was 5'-TCTGGCTCTTCTCGGAGGTCA-3', that reduced the dose-dependently synthesis of POMC cleavage-derived hormones ( $\beta$-endorphin, ACTH, $\alpha$-MSH, $\beta$-MSH, $\gamma$-MSH) in in vivo and in vitro models $[18,22,24]$. In order to avoid the potential confusing factor of a huge decrease in the activity of the HPA axis, we selected an AS dose $(0.1 \mathrm{nmol} / \mathrm{g})$, which has been able to reduce the increased hormone levels induced by stress while has not been capable of reducing the basal level of the POMC-derived molecules found in control (CTR) mice [22]. There is no apparent toxic effect produced by AS's repeated administration in the neonate and adult mice [18,22].

\section{Stress procedures}

Experiments were performed following procedures published in our previous studies [18,22]. In brief, stress procedures were conducted during the winter period, in order to avoid seasonal variations in the receptor's sensitivity. Following the arrival of females from the factory on the $14^{\text {th }}$ day of pregnancy, starting on the $19^{\text {th }}$ day of pregnancy, females were examined twice per day (at 08:00 and 16:00) to control the presence of pups. All male pups born in the 12 hours' window belonging to different litters were put together, with the exclusion of a few animals whose weight was over the mean \pm 2 standard deviations. All accepted pups weighed between 2.01 and $2.69 \mathrm{~g}$, with a normal distribution. Within 12 hours since birth, six male pups of homogeneous size were put together and randomly assigned per litter, so that all pups were randomly cross-fostered. Litters were casually assigned to one of the following groups: 1) CTR mice: the pups were left undisturbed, but pups and dams were removed at the same time and put together in a clean cage twice per week; 2) stressed mice (SM): from postnatal day (PND) 2 up to PND 21, pups were removed daily, all at the same moment, from the home cage and grouped in a container with a fresh bedding material for $10 \mathrm{~min}$. During this period, each pup of stressed groups was gently picked up with a gloved hand, weighed, and injected subcutaneously on its back 
with sterile saline solution $(1 \mu \mathrm{l} / \mathrm{g}$ ) with a micro-syringe (26-gauge needle). After that, they were returned all together to the home cage with the mother; 3) AS group was submitted to the same stressing procedures, but it was treated with AS-POMC $(0.1 \mathrm{nmol} / \mathrm{g})$ in saline solution $(1 \mu \mathrm{l} / \mathrm{g})$. Procedures were always carried out by the same experimenter. Thereby, animals received two different stressful procedures: psychological stress, i.e. daily short mother separation from PND 2 to PND 21, and slight pain stress, i.e. daily sham injection from PND 2 to PND 21. It is of no relevance at all the fact that mice were born from mothers shipped during pregnancy because all mice could also undergo intrauterine stress. Nevertheless, our CTR mice present physiological levels of GCs and glycemia, even though prenatal stress by shipping has previously been shown to have no significant effect on the metabolic profile and basal corticoids blood levels in adult offspring [25]. However, we cannot exclude a contribution of prenatal stress in the development of the phenotype of adult hypercortisolism. At PND 21, tissues were dissected from sacrificed mice from all experimental groups, and hormonal levels were evaluated. The rest of the animals were rehoused in post-weaning cages, placing two or three animals of the same experimental group in each cage to prevent isolation-induced stress. At PND 90, animals were sacrificed and tissues dissected and analyzed. The timing of experimental procedures is described in Table 1.

\section{Glycemia testing}

Since fasting during the lactation period could affect the model, only at the age of 90 PND, a part of the mice selected from each group has been submitted to the test for glycemia. In order to prevent a potential stress induced by fasting, plasma from these mice has not been used to analyze stress hormones. The collection of blood for all determinations, including glycemia, took place immediately after decapitation by gathering trunk blood. The test was performed in the morning, after 12-hour fasting, using test strips and a glucometer (One-Touch EuroFlash; Johnson \& Johnson Co). Each test was repeated twice, and the mean of the two measures was recorded.

\section{Plasma and tissue preparations}

Since mice have an inverted light/dark cycle compared to the humans' one, at 21 and 90 PND non-fasting animals have immediately been sacrificed between 09:00 and 12:00 in the noon, to identify hypercortisolism and classify also the ACTH status [26]. In order to avoid possible differences in stress procedures, the animals from one of the cages were picked up by three investigators at the time and gone through the experimental procedure at the same time.

Trunk blood was collected in either ice-chilled heparinized or in EDTA-containing tubes according to each hormone-specific assay protocol and spun at $3,500 \times g$ for 10 minutes at $4{ }^{\circ} \mathrm{C}$. Plasma was stored at $-80{ }^{\circ} \mathrm{C}$ until assayed. The total pituitary gland and the hypothalamus were dissected on dry ice and stored at $-80{ }^{\circ} \mathrm{C}$, following previously described procedures $[27,28]$. Before storing, pituitary glands of CTR and SM at 90 PND were weighted. On 
the day of assay, according to Spampinato and Goldstein [29], tissues were extracted in $0.1 \mathrm{mM}$ acetic acid at $90{ }^{\circ} \mathrm{C}$ and used throughout.

\section{Immune-reactive (ir-)ACTH, ir-CRH and ir-corticosterone determinations}

Tissue and plasma $i r$-CRH and $i r$-ACTH were measured with a double-antibody precipitation radioimmunoassay (RIA) [30]. The hACTH antibody (Dr. A.F. Parlow, Harbor-UCLA Medical Center, USA) fully recognizes mouse ACTH (139) and there is no significant cross-reactivity with other peptides derived from the proopiomelanocortin precursor [17]. In the same way, the mouse CRH antibody (Bachem AG, Bubendorf, Switzerland), shows no relevant cross-reactivity with other peptides derived from-CRH precursor [22]. The detection limit for $\mathrm{ACTH}$ was $6 \pm 0.23 \mathrm{pg} / \mathrm{ml}$; IC $\mathrm{IC}_{50}$ was $229 \pm 26 \mathrm{pg} / \mathrm{ml}$ (mean \pm S.D.); whereas CRH detection limit was $3 \pm 0.12 \mathrm{pg} / \mathrm{ml}$; $\mathrm{IC}_{50}$ was $14.7 \pm 1.5 \mathrm{pg} / \mathrm{ml}$ (mean \pm S.D.). $\left[{ }^{125} \mathrm{I}\right]$ iodotyrosyl2 $-\mathrm{ACTH}(1-39)\left[{ }^{125} \mathrm{I}\right]$ iodotyrosyl ${ }^{0}$-CRH were purchased from Amersham Biosciences (Milan, Italy) and Bachem AG (Bubendorf, Switzerland).

Ir-corticosterone-like material was assayed with RIA kits (ICN, Costa Mesa, CA, USA) as previously pointed out [31]. All assays were measured in duplicate and all determinations had intra-assay and inter-assay variations less than $2 \%$. Tissue proteins were measured as previously reported $[18,22,32,33]$.

\section{Statistics}

Results are presented as the mean \pm standard error $( \pm$ SE) of single animal data. Statistical analysis was performed using GraphPad Prism (version 7.05). All datasets were analyzed using the Brown-Forsythe test for normality. Datasets with normal distribution were analyzed for significance using one-way or two-way analysis of variance (ANOVA). Post hoc multiple comparisons were carried out using the Tukey's multiple comparisons or the Bonferroni post hoc test. Datasets with nonparametric distribution were analyzed using the Kruskal-Wallis test. Post hoc multiple comparisons were performed using the two-stage linear step-up procedure of Benjamini, Krieger, and Yekutieli. F-, H- and P values for individual statistical analyses, and post-hoc analyses, are reported in Table 2. A probability level of $\mathrm{P}<0,05$ was considered to be statistically significant.

\section{Results}

\section{Bodyweight and metabolic parameters}

Fig. 1 shows the pattern of body weight in CTR, SM, and AS male mice at different ages: from the end of the daily administered stress during the nursing period at 21 PND up to 90 PND. At 90 PND, SM showed a significant increment in total body weight compared to CTR and AS (Fig. 1A). In Fig. 1B, at 90 PND the post-hoc test shows that stress 
procedures triggered a consistent increase in fasting glycemia levels in adult age, while AS prevents completely stressinduced hyperglycemia.

\section{Hormonal parameters}

Stress hormones' expressions, recorded 30 minutes after (21 PND) and 70 days after the stressful period (90 PND) are reported for all experimental groups in Figure 2 and 3. At 21 PND in SM we observed an increase in the hypothalamic CRH and ACTH (hACTH) expression's level, considered archetype of all POMC derived peptides, respect to CTR (Fig. 2A and 2B, respectively), as well as an enhanced pituitary ACTH (pACTH) level (Fig. 3A) in SM vs the other groups. The SM also have circulating ACTH (cACTH) (Fig. 3B) and corticosterone (Fig. 3C) levels consistently higher than those of CTR and AS-treated mice.

After the unstressed period (90 PND), in hypothalamic dissected tissues from SM the CRH and hACTH levels were significantly lower and suppressed compared to that of the other groups (Fig. 2), whereas pACTH expression's level remains higher than in CTR and AS-treated mice (Fig. 3A). Both cACTH (Fig. 3B) and corticosterone levels (Fig. 3C) were higher in stressed animals than in CTR and AS-treated mice. The weights of fresh pituitary glands from SM were significantly higher than in control mice (Fig. 4).

\section{Discussion}

The present data confirm and extend the understanding of the pathogenic role of ES [19]. These results show that immediately after the stress procedures, CD-1 male mice present a transient rise of $\mathrm{CRH}$ expression, that decreases thereafter and appears to be suppressed at 90 PND. Simultaneously, we have observed a progressive increment of both pituitary and circulating $\mathrm{ACTH}$, as well as corticosterone plasma levels, which persisted from 21 up to $90 \mathrm{PND}$. These findings are accompanied by an increase in the total body weight curve, which becomes significantly higher after the unstressed period (from 21 to 90 PND). The treatment with AS-POMC prevents almost all the hormonal and metabolic alterations reported in SM, which may prevent not only pituitary ACTH secretion but also the activation of the CRH neurons during the stress phase [34]. Indeed, while measuring the hACTH, as an archetype of all POMC-derived peptides, we have detected different levels of this peptide in the experimental groups that are consistent with CRH trend. Since POMC (and ACTH itself) is the precursor of various MSH peptides able to act on melanocortin receptors [35,36], our data suggest a fundamental role of hypothalamic POMC positive neurons during stress, since the blunting of POMC expression by an AS can prevent the stress mediated CRH activation of the axis. Thereby, it is conceivable that, by acting on hypothalamic POMC neurons, the AS-POMC could have reduced the POMC-derived molecules, which are known to influence the responsiveness of hypothalamic neurons to stress. Furthermore, at 90 days, after being 
stressed in early-life, mice, but in the absence of active stress condition, could have developed an autonomous pituitary ACTH secretion. Indeed, the consequent high corticosterone circulating levels have been effective on the negative feedback only at the hypothalamic level, thus eventually decreasing CRH secretion (Fig. 5). Moreover, as a consequence of the prevention of $\mathrm{CRH}$ rise during the stress period, the treatment with AS-POMC is associated with normal expression levels of CRH and pituitary ACTH and, in consequence, of normal circulating parameters of HPA axis throughout the study period $[37,38]$.

The proposed pathogenic mechanism is in line with what have been published on the transgenic mouse model of CS, which is associated with stress-like neuroendocrine and autonomic changes and developing high corticosterone plasma levels and adrenal gland hypertrophy, due to an enduring hypothalamic CRH overexpression. In those studies, the basal plasma ACTH concentrations were not suppressed (as one would have expected in the presence of normal pituitary feedback due to GC excess), consistent with a partially autonomous ACTH hypersecretion [39]. Interestingly, the GC excess in our model appears clearly as ACTH-dependent because the hypothalamic CRH overexpression is restricted to the stress period during early-life, and is thereafter suppressed by the GC feedback. The increase in body weight as well as mild hyperglycemia, are also consistent with the development of a Cushing-like condition in the SM [40,41].

The whole body of these data suggests that a metabolic syndrome (overweight/hyperglycemia/hypertension) may originate from juvenile stress, which may induce a constant ACTH-dependent GC excess persisting even after the resolution of the stressful period of time. Furthermore, the possibility that stressful events in early-life could be associated with the occurrence of an ACTH autonomous secretion had already been proposed by other authors, who have observed that patients with a pituitary-dependent CS have had a relevant number of stressful events more in their youth rather than a normal control group [9]. On the other hand, the strict association of metabolic syndrome and GC excess, even of a mild degree, has been suggested by studies showing that a hidden hypercortisolism is more frequent than what was expected among patients with type 2 diabetes $[11,12,42,43]$. While we are aware that neuropsychological alterations are common in patients with clinically overt CS [44], in patients with less severe hypercortisolism data are scarce, but even the condition of subtle GC excess may influence patients' mental health and cognitive performance [45]. Moreover, recent studies imply that even in subjects without hypercortisolism, an increased degree of cortisol secretion (even though still within the normal range) is associated with the typical chronic complications of hypercortisolism (i.e. diabetes, hypertension, and osteoporosis) [46,47]. Therefore, it is conceivable that the stress condition, by increasing cortisol secretion, may lead to chronic consequences typical of CS [48].

Further studies are needed to identify other possible "actors" that could affect the proposed pathogenic mechanism, such as the arginine-vasopressin hormone (AVP), which is known to influence ACTH secretion. However, 
the clear effect of AS-POMC in normalizing the HPA axis alterations and the low AVP expression in paraventricular nucleus (PVN) CRH neurons, presented by other authors [9], suggests that CRH has the main role in mediating the ACTH hypersecretion in our model. Moreover, in the same way as our findings, it is reported a decrease in steady-state mRNA levels of CRH in the PVN of ES-experiencing pups, with an increase in corticosterone blood levels. By contrast, it was not observed a significant change in mRNA levels of arginine vasopressin in the hypothalamus of these mice [48]. In addition to the lack of AVP measurement, our study has other limitations. Firstly, we have not evaluated the changes in the GC receptor's expression that may influence different sensitivity in the negative feedback at the hypothalamic or pituitary level [49]. However, the consistency of the data obtained after POMC-AS administration suggests that the GC receptor's differences shall exert a minimal role in the pathogenesis of this persistent ACTH hypersecretion after stress in early-life. Secondly, we do still not know if the early stress is effectively associated with the development of corticotroph adenomas or with an increased function of the whole corticotroph population. The lack of a pituitary imaging and/or pituitary tissue investigation precludes us from solving this issue, however the observed increase in pituitary weight in SM (Fig. 4) prompts further studies on this model with histological analyses of pituitary tissue. Thirdly, in the hypothalamic tissue, we have not measured changes in POMC mRNA or POMC products other than ACTH in the adult mice following stress exposure.

Despite all these limitations, the HPA axis activity alterations of this mouse model may be consistent with the idea of an initial hypothalamic origin of the ACTH-secreting pituitary hyperplasia [50], which could promote corticotroph proliferation leading later on to an autonomous ACTH secretion.

In conclusion, these findings suggest that a chronic stress in early-life can induce a persistent up-regulation of the HPA axis generating endocrine, metabolic and somatic alterations very similar to those found in human ACTHdependent autonomous cortisol hypersecretion [13].

\section{Declaration}

\section{Funding}

This research did not receive any specific grant from any funding agency in the public, commercial or not-for-profit sector. The research activity of AF, LP and IC is partially supported by the Ricerca Corrente funds of IRCCS Istituto Auxologico Italiano (code: 05C921_2019).

\section{Conflicts of interest}

Authors declare that there is no conflict of interest that could be perceived as prejudicing the impartiality of the research reported. 


\section{Ethics approval}

All the procedures were carried out in accordance with the guidelines of the Council of European Communities

(European Communities Council Directive of 24 November 1986, 86/609/EEC) and following the approval of the

Bioethical Committee of the Italian National Institute of Health (Istituto Superiore di Sanità - ISS), and the Italian

Ministry of Health.

\section{Availability of data and material}

Data will be made available upon request.

\section{References}

1. J. K. Gjerstad, S. L. Lightman, and F. Spiga, Role of glucocorticoid negative feedback in the regulation of HPA axis pulsatility. Stress 21, 403 (2018).

2. E. T. Uchoa, G. Aguilera, J. P. Herman et al. Novel aspects of glucocorticoid actions. J. Neuroendocrinol. 26, 557 (2014).

3. N. C. Vamvakopoulos and G. P. Chrousos, Hormonal regulation of human corticotropin-releasing hormone gene expression: implications for the stress response and immune/inflammatory reaction. Endocr. Rev. 15, 409 (1994).

4. A. M. Bao and D. F. Swaab, The human hypothalamus in mood disorders: The HPA axis in the center. IBRO Reports 6, 45 (2019).

5. A. Chatzittofis, S. Arver, K. Öberg et al. HPA axis dysregulation in men with hypersexual disorder. Psychoneuroendocrinology 63, 247 (2016).

6. F. Xiong and L. Zhang, Role of the hypothalamic-pituitary-adrenal axis in developmental programming of health and disease. Front. Neuroendocrinol. 34, 27 (2013).

7. A. Agorastos, P. Pervanidou, G. P. Chrousos et al. Developmental Trajectories of Early Life Stress and Trauma: A Narrative Review on Neurobiological Aspects Beyond Stress System Dysregulation. Front. Psychiatry 10, 118 (2019).

8. O. Cooper, V. Bonert, F. Moser, et al. Altered Pituitary Gland Structure and Function in Posttraumatic Stress Disorder. J. Endocr. Soc. 1, 577 (2017).

9. N. Sonino, G. A. Fava, S. Grandi et al. Stressful life events in the pathogenesis of Cushing's syndrome. Clin. Endocrinol. (Oxf). 29, 617 (1988).

10. N. Sonino, G. A. Fava, and M. Boscaro. A role for life events in the pathogenesis of Cushing's disease. Clin. Endocrinol. (Oxf). 38, 261 (1993). 
11. B. Catargi, V. Rigalleau, A. Poussin et al. Occult Cushing's syndrome in type-2 diabetes. J. Clin. Endocrinol. Metab. 88,5808 (2003).

12. Chiodini, M. Torlontano, A. Scillitani et al. Association of subclinical hypercortisolism with type 2 diabetes mellitus: a case-control study in hospitalized patients. Eur. J. Endocrinol. 153, 837 (2005).

13. J. W. Findling and H. Raff, DIAGNOSIS OF ENDOCRINE DISEASE: Differentiation of pathologic/neoplastic hypercortisolism (Cushing's syndrome) from physiologic/non-neoplastic hypercortisolism (formerly known as pseudo-Cushing's syndrome). Eur. J. Endocrinol. 176, R205 (2017).

14. E. B. Geer, J. Islam, and C. Buettner. Mechanisms of glucocorticoid-induced insulin resistance: focus on adipose tissue function and lipid metabolism. Endocrinol. Metab. Clin. North Am. 43, 75 (2014).

15. H. Raff and T. Carroll, Cushing's syndrome: from physiological principles to diagnosis and clinical care. J. Physiol. 593, 493 (2015).

16. C. Steffensen, O. M. Dekkers, J. Lyhne et al. Hypercortisolism in Newly Diagnosed Type 2 Diabetes: A Prospective Study of 384 Newly Diagnosed Patients. Horm. Metab. Res. 51, 62 (2019).

17. A. Loizzo, S. Loizzo, G. Galietta, et al. Overweight and metabolic and hormonal parameter disruption are induced in adult male mice by manipulations during lactation period. Pediatr. Res. 59, 111 (2006).

18. S. Loizzo, G. Campana, S. Vella, et al. Post-natal stress-induced endocrine and metabolic alterations in mice at adulthood involve different pro-opiomelanocortin-derived peptides. Peptides 31, 2123 (2010).

19. A. Loizzo, S. M. Spampinato, G. Campana, et al. Etiopathogenesis and Pharmacological Prevention of a Type-2 Diabetes Model in Male Mice. J. Pharmacol. Exp. Ther. 364, 347 (2018).

20. N. C. Victoria and A. Z. Murphy, The long-term impact of early life pain on adult responses to anxiety and stress: Historical perspectives and empirical evidence. Exp. Neurol. 275, 261 (2016).

21. S. M. Mooney-Leber and S. Brummelte, Neonatal pain and reduced maternal care alter adult behavior and hypothalamic-pituitary-adrenal axis reactivity in a sex-specific manner. Dev. Psychobiol. 62, 631 (2019).

22. G. Galietta, A. Loizzo, S. Loizzo, et al. Administration of antisense oligonucleotide against pro-opiomelanocortin prevents enduring hormonal alterations induced by neonatal handling in male mice. Eur. J. Pharmacol. 550, 180 (2006).

23. A. Loizzo, S. M. Spampinato, A. Fortuna, et al. Antisense versus proopiomelanocortin mRNA reduces vascular risk in a murine model of type-2 diabetes following stress exposure in early post-natal life. Peptides 64, 34 (2015).

24. S. Spampinato, M. Canossa, L. Carboni, et al. Inhibition of proopiomelanocortin expression by an oligodeoxynucleotide complementary to beta-endorphin mRNA. Proc. Natl. Acad. Sci. U. S. A. 91, 8072 (1994). 
25. R. M. Philpot, M. E. Engberg, and L. Wecker, Effects of nicotine exposure on locomotor activity and pCREB levels in the ventral striatum of adolescent rats. Behav. Brain Res. 230, 62 (2012).

26. M. John, A. R. Lila, T. Bandgar, et al. Diagnostic efficacy of midnight cortisol and midnight ACTH in the diagnosis and localisation of Cushing's syndrome. Pituitary 13, 48 (2010).

27. S. C. Tzou, M. A. Landek-Salgado, H. Kimura, et al. Preparation of mouse pituitary immunogen for the induction of experimental autoimmune hypophysitis. J. Vis. Exp. 46, 2182 (2010).

28. M. K. Gill, S. Karanth, A. Dutt, et al. Effect of castration and steroid treatment on the release of gonadotropins by the rat pituitary-hypothalamus complex in vitro. Horm. Metab. Res. 17, 141 (1985).

29. S. Spampinato and A. Goldstein, Immunoreactive dynorphin in rat tissues and plasma. Neuropeptides 3, 193 (1983).

30. W. E. Nicholson, D. R. Davis, B. J. Sherrell, et al. Rapid radioimmunoassay for corticotropin in unextracted human plasma. Clin. Chem. 30, 259 (1984).

31. F. Fontana, P. Bernardi, E. M. Pich, et al. Opioid peptide modulation of circulatory and endocrine response to mental stress in humans. Peptides 18, 169 (1997).

32. M. M. Bradford, Anal. Biochem. A rapid and sensitive method for the quantitation of microgram quantities of protein utilizing the principle of protein-dye binding. 72, 248 (1976).

33. S. Loizzo, S. Vella, A. Loizzo, et al. Sexual dimorphic evolution of metabolic programming in non-genetic nonalimentary mild metabolic syndrome model in mice depends on feed-back mechanisms integrity for proopiomelanocortin-derived endogenous substances. Peptides 31, 1598 (2010).

34. V. Mela, F. Díaz, M. J. Vázquez, et al. Interaction between neonatal maternal deprivation and serum leptin levels on metabolism, pubertal development, and sexual behavior in male and female rats. Biol. Sex Differ. 7, 2 (2016).

35. R. M. Dores, Adrenocorticotropic hormone, melanocyte-stimulating hormone, and the melanocortin receptors: Revisiting the work of robert schwyzer: A thirty-year retrospective. in Ann. N. Y. Acad. Sci. (Blackwell Publishing Inc., 2009), pp. 93-100.

36. R. D. Cone, Studies on the physiological functions of the melanocortin system. Endocr. Rev. 27, 736 (2006).

37. J. P. Herman and J. G. Tasker, Paraventricular Hypothalamic Mechanisms of Chronic Stress Adaptation. Front. Endocrinol. (Lausanne). 7, 137 (2016).

38. C. J. Rice, C. A. Sandman, M. R. Lenjavi, et al. A novel mouse model for acute and long-lasting consequences of early life stress. Endocrinology 149, 4892 (2008).

39. L. Groenink, A. Dirks, P. M. Verdouw, et al. HPA axis dysregulation in mice overexpressing corticotropin releasing hormone. Biol. Psychiatry 51, 875 (2002). 
40. M. J. Lee, P. Pramyothin, K. Karastergiou, et al. Deconstructing the roles of glucocorticoids in adipose tissue biology and the development of central obesity. Biochim. Biophys. Acta 1842, 473 (2014).

41. C. Scaroni, M. Zilio, M. Foti, et al. Glucose Metabolism Abnormalities in Cushing Syndrome: From Molecular Basis to Clinical Management. Endocr. Rev. 38, 189 (2017).

42. L. C. Martins, F. L. Conceição, E. S. Muxfeldt, et al. Prevalence and associated factors of subclinical hypercortisolism in patients with resistant hypertension. J. Hypertens. 30, 967 (2012).

43. M. Terzolo, G. Reimondo, I. Chiodini, et al. Screening of Cushing's syndrome in outpatients with type 2 diabetes: results of a prospective multicentric study in Italy. Clin. Endocrinol. Metab. 97, 3467 (2012).

44. R. Pivonello, A. M. Isidori, M. C. De Martino, et al. Complications of Cushing's syndrome: state of the art. Lancet Diabetes Endocrinol. 4, 611 (2016).

45. V. Morelli, C. Aresta, A. Gaudio et al. Prediction of hypertension, diabetes and fractures in eucortisolemic women by measuring parameters of cortisol milieu. Endocrine 68, 411 (2020).

46. V. Morelli, A. Ghielmetti, A. Caldiroli et al. Mental health in patients with adrenal incidentalomas: is there a relation with different degrees of cortisol secretion? J Clin Endocrinol Metab. dgaa695 (2020).

47. V. Morelli, C. Aresta, A. Gaudio et al. Prediction of hypertension, diabetes and fractures in eucortisolemic women by measuring parameters of cortisol milieu. Endocrine 68, 411 (2020).

48. G. Tirabassi, M. Boscaro, and G. Arnaldi, Harmful effects of functional hypercortisolism: a working hypothesis. Endocrine 46, 370 (2014).

49. V. Morelli, F. Donadio, C. Eller-Vainicher, et al. Role of glucocorticoid receptor polymorphism in adrenal incidentalomas. Eur. J. Clin. Invest. 40, 803 (2010).

50. R. N. Clayton and W. E. Farrell, Pituitary tumour clonality revisited. Front. Horm. Res. 32, 186 (2004).

\section{Figure legends}

\section{Table 1}

\section{Stress procedures' timing.}

Table 2

\section{Statistical analysis.}

\section{Figure 1}

Metabolic parameters. Total body weight (A) and fasting glycemia (B). (A) Total body weights at 21 ( $n=8$ per group), 30 ( $n=6$ per group), 60 ( $n=12$ per group), and 90 ( $n=12$ per group) days of age in the three groups of mice. CTR indicates the undisturbed mice group; SM indicates mice underwent stress procedures; AS indicates SM treated with 
antisense-POMC. Statistical analyses were performed using ANOVA and analyzed using the Bonferroni post hoc test, (B) fasting glycemia ( $n=6$ per group) were performed using ANOVA followed by the Tukey's multiple comparisons test. Values are expressed as mean $\pm \mathrm{SE} . * \mathrm{P}<0.05 ; * * * \mathrm{P}<0.001$ for $\mathrm{CTR}$ vs $\mathrm{SM} .{ }^{\S} \mathrm{P}<0.01$ for $\mathrm{SM}$ vs AS.

\section{Figure 2}

Hypothalamic parameters. Immunoreactive content of hypothalamic ACTH (hACTH) (A) or CRH (B) of mice at 21 PND ( $n=6-7$ per group) and 90 PND ( $n=5$ per group). Values are expressed as mean \pm SE. Statistical analysis was performed depending on the distribution parametricity of data. Datasets with normal distribution were analyzed for significance using a one-way analysis of variance or two-way (ANOVA). Post hoc multiple comparisons were carried out using the Tukey's multiple comparisons or the Bonferroni's post hoc test. Datasets with nonparametric distribution were analyzed using the Kruskal-Wallis test. Post hoc multiple comparisons were carried out using the two-stage linear step-up procedure of Benjamini, Krieger and Yekutieli, $* \mathrm{P}<0.05$; $* * * \mathrm{P}<0.001$ for $\mathrm{CTR}$ vs other groups. ${ }^{\S} \mathrm{P}<0.05$, $\S \S \mathrm{P}<0.001$ for $\mathrm{SM}$ vs AS.

\section{Figure 3}

Pituitary and plasmatic parameters. Pituitary content of pACTH (A) and circulating cACTH (B) and corticosterone (C) of mice at 21 PND ( $n=6-7$ per group) and 90 PND ( $n=5$ per group). Values are expressed as mean \pm SE. Statistical analysis was performed depending on the distribution parametricity of data. Datasets with normal distribution were analyzed for significance using a one-way analysis of variance (ANOVA). Post hoc multiple comparisons were carried out using the Tukey's multiple comparisons test. Datasets with nonparametric distribution were analyzed using the Kruskal-Wallis test. Post hoc multiple comparisons were carried out using the two-stage linear step-up procedure of Benjamini, Krieger and Yekutieli, *** $\mathrm{P}<0.001$ for CTR vs SM. ${ }^{\S} \mathrm{P}<0.01$ for $\mathrm{SM}$ vs AS.

\section{Figure 4}

\section{Pituitary weights.}

Weights of fresh pituitary glands of control and stressed mice at 90 PND ( $n=5$ per group). Values are expressed as mean \pm SE. Statistical analysis was performed depending on the distribution parametricity of data. Datasets were analyzed for significance using an unpaired t-test, ${ }^{*} \mathrm{P}<0.05$ for CTR vs SM.

\section{Figure 5}

Summary scheme. Our data are consistent with an autonomous corticotropin secretion in 90 PND mice undergoing a stressful treatment in early life. 


\section{Early post-natal life stress induces permanent adrenocorticotropin-dependent 1 \\ hypercortisolism in male mice}

Gabriele Campana ${ }^{1}$ • Stefano Loizzo ${ }^{2}$ - Andrea Fortuna ${ }^{2}$ Roberto Rimondini ${ }^{3}$ - Zaira Maroccia ${ }^{2}$.

Alfredo Scillitani ${ }^{4}$ • Alberto Falchetti ${ }^{5} \cdot$ Santi Mario Spampinato $^{1} \cdot$ Luca Persani $^{5,6} \S$ Iacopo Chiodini ${ }^{5,6 \S}$

${ }^{1}$ Department of Pharmacy and Biotechnology, University of Bologna, Via Irnerio 48, 40126, Bologna, Italy

${ }^{2}$ Department of Cardiovascular and Endocrine-Metabolic Diseases and Aging, Istituto Superiore di Sanità, Viale Regina Elena 299, 00161, Rome, Italy

${ }^{3}$ Department of Medical and Clinical Sciences, University of Bologna, Via Irnerio 48, 40126, Bologna, Italy

${ }^{4}$ Endocrinology and Diabetology, Ospedale "Casa Sollievo della sofferenza" IRCCS, Viale Cappuccini 1, 71013, San Giovanni Rotondo, Foggia, Italy

${ }^{5}$ Department of Clinical Sciences and Community Health, University of Milan, Via della Commenda 19, 20122, Milan, Italy

${ }^{6}$ Division of Endocrine and Metabolic Diseases \& Lab. of Endocrine and Metabolic Research, IRCCS Istituto Auxologico Italiano, Piazzale Brescia 20, 20149 Milan, Italy.

$\S$ Equal author contribution

\section{Corresponding author: Stefano Loizzo}

E-mail: stefano.loizzo@iss.it

ORCID: 0000-0001-6344-2613

Key words: Cushing's syndrome · Pituitary ACTH hypersecretion · Metabolic syndrome $\cdot$ Early-life stress · Mouse.

Acknowledgments: Thanks are due to Alberto Loizzo for support and helpful comments that have improved our work, to Andrea Martinelli, Paolo Frassanito, and Flavio Torriani (ISS) for valuable animal care. 


\section{Abstract}

Purpose It has been hypothesized that specific early-life stress (ES) procedures on CD-1 male mice produce diabeteslike alterations due to the failure of negative feedback of glucocorticoid hormone in the pituitary. The aim of this study is to investigate the possible mechanism that leads to this pathological model, framing it in a more specific clinical 9 condition.

Methods Metabolic and HPA-related hormones of stressed mice (SM) have been analyzed immediately after stress procedures (21 postnatal day, PND) and after 70 days of a peaceful (unstressed) period (90PND). These data have been compared to parameters from age-matched controls (CTR), and mice treated during ES procedures with oligonucleotide antisense for pro-opiomelanocortin (AS-POMC).

Results At 21PND, SM presented an increased secretion of hypothalamic $C R H$ and pituitary POMC-derived peptides, as well as higher plasmatic levels of $A C T H$ and corticosterone vs CTR. At 90PND, SM showed hyperglycemia, with alse suppression of hypothalamic $C R H$, while pituitary and plasmatic $A C T H$ levels, as well as plasma corticosterone, were constantly higher than in CTR. These values are accompanied by a progressive acceleration in gaining total body weight, which became significant versus CTR at 90PND together with a higher pituitary weight. Treatment with ASPOMC prevented all hormonal and metabolic alterations observed in SM, both at 21 and 90PND.

Conclusion These findings show that these specific ES procedures affect the negative glucocorticoid feedback in the pituitary, but not in the hypothalamus, suggesting a novel model of ACTH-dependent hypercortisolism that can be prevented by silencing the $P O M C$ gene. 


\section{Introduction}

1

The hypothalamic-pituitary-adrenal (HPA) axis is a complex set of direct influences and feedback interactions among three components: the hypothalamus, the pituitary gland, and the adrenal glands [1,2]. Since HPA axis is a major neuroendocrine system, it is in charge of controlling the reactions to stress and regulates many body processes, including the immune system [3], mood and emotions [4], sexual desire regulation [5], and energy storage and consumption [2]. Thereby, an alteration of the HPA axis homeostasis can lead to behavioral disorders and metabolic diseases [6].

As it is known, the HPA axis has intrinsic plasticity in the early-life's phases in humans [7]. Indeed, this situation could explain much evidences and suggest that conditions of stress might alter the HPA axis activity, which leads consequently to glucocorticoids (GCs) hypersecretion [8]. In past times, it has already been proposed to maintain an occasional relationship between Cushing's syndrome (CS) and stress conditions throughout infancy $[9,10]$.

The condition of hypercortisolism provokes some of the hallmark signs as insulin resistance, dyslipidemia, vascular alterations, bone fragility, and body overweight [11-16]. Interestingly, these findings are similar to the phenotype of early-life stress (ES) mouse model developed in our laboratories [17-19]. Likewise other ES models [20,21], this mouse is submitted to complex ES procedures that could mimic the neonatal intensive care unit. After an unstressed period of 70 days, the mice present hyperglycemia, hyperinsulinemia, and body overweight, caused by a persisting GCs surplus $[17,22,23]$, which may be associated with an up-regulation of the negative GCs feedback mechanisms [19].

Thus, this mouse's pathology presents itself as a suitable model for clarifying the relationship between chronic stress in early-life and the related HPA axis activation, as a possible pathogenic cause of hypercortisolism.

To understand the early stress-related pathogenesis of this model, we have been analyzing the hypothalamus and pituitary expression, and circulating hormones at different ages (immediately after stress procedures and after 70 days under unstressed conditions). These results have been compared with those obtained as much in unstressed mice as in stressed mice, treated with antisense oligodeoxynucleotide versus pro-opiomelanocortin (AS-POMC, or AS).

\section{Material and methods}

\section{Ethics guidelines}

All the procedures were carried out in accordance with the guidelines of the Council of European Communities (European Communities Council Directive of 24 November 1986, 86/609/EEC) and following the approval of the Bioethical Committee of the Italian National Institute of Health (Istituto Superiore di Sanità - ISS), and the Italian Ministry of Health. All possible efforts have been made to minimize animal suffering and to reduce the number of 
animals used. For the current investigation, no alternatives to in vivo techniques are available. We confirm that all mandatory laboratory health and safety procedures have been complied throughout the course of any experimental work presented in this paper.

\section{Animal general procedures}

Pregnant multiparous outbred laboratory-born CD-1 mice were sent by the factory (Charles River Italia, Calco, Italy) and arrived at the $14^{\text {th }}$ day of conception age in the ISS vivarium; all mice were housed in single cages in a central facility and maintained under controlled conditions of $55 \pm 5 \%$ humidity and temperature of $21 \pm 1{ }^{\circ} \mathrm{C}$, in a photoperiod of 12 hours' light and dark, with the light turned on at 07:00. Mice were fed a standard $(6.55 \% \mathrm{kcal}$ from fat and 3.9 kcal/g; 4RF21, Mucedola, Italy) diet, food, and water are available ad libitum.

\section{Drugs}

AS-POMC was produced by EUROBIO Laboratories (Les Ulis Cedex, France). The 21-base sequence of AS-POMC was 5'-TCTGGCTCTTCTCGGAGGTCA-3', that reduced the dose-dependently synthesis of POMC cleavage-derived hormones ( $\beta$-endorphin, ACTH, $\alpha$-MSH, $\beta$-MSH, $\gamma$-MSH) in in vivo and in vitro models $[18,22,24]$. In order to avoid the potential confusing factor of a huge decrease in the activity of the HPA axis, we selected an AS dose $(0.1 \mathrm{nmol} / \mathrm{g})$, which has been able to reduce the increased hormone levels induced by stress while has not been capable of reducing the basal level of the POMC-derived molecules found in control (CTR) mice [22]. There is no apparent toxic effect produced by AS's repeated administration in the neonate and adult mice [18,22].

\section{Stress procedures}

Experiments were performed following procedures published in our previous studies [18,22]. In brief, stress procedures were conducted during the winter period, in order to avoid seasonal variations in the receptor's sensitivity. Following the arrival of females from the factory on the $14^{\text {th }}$ day of pregnancy, starting on the $19^{\text {th }}$ day of pregnancy, females were examined twice per day (at 08:00 and 16:00) to control the presence of pups. All male pups born in the 12 hours' window belonging to different litters were put together, with the exclusion of a few animals whose weight was over the mean \pm 2 standard deviations. All accepted pups weighed between 2.01 and $2.69 \mathrm{~g}$, with a normal distribution. Within 12 hours since birth, six male pups of homogeneous size were put together and randomly assigned per litter, so that all pups were randomly cross-fostered. Litters were casually assigned to one of the following groups: 1) CTR mice: the pups were left undisturbed, but pups and dams were removed at the same time and put together in a clean cage twice per week; 2) stressed mice (SM): from postnatal day (PND) 2 up to PND 21, pups were removed daily, all at the same moment, from the home cage and grouped in a container with a fresh bedding material for $10 \mathrm{~min}$. During this period, each pup of stressed groups was gently picked up with a gloved hand, weighed, and injected subcutaneously on its back 
with sterile saline solution $(1 \mu \mathrm{l} / \mathrm{g}$ ) with a micro-syringe (26-gauge needle). After that, they were returned all together to the home cage with the mother; 3) AS group was submitted to the same stressing procedures, but it was treated with AS-POMC $(0.1 \mathrm{nmol} / \mathrm{g})$ in saline solution $(1 \mu \mathrm{l} / \mathrm{g})$. Procedures were always carried out by the same experimenter. Thereby, animals received two different stressful procedures: psychological stress, i.e. daily short mother separation from PND 2 to PND 21, and slight pain stress, i.e. daily sham injection from PND 2 to PND 21. It is of no relevance at all the fact that mice were born from mothers shipped during pregnancy because all mice could also undergo intrauterine stress. Nevertheless, our CTR mice present physiological levels of GCs and glycemia, even though prenatal stress by shipping has previously been shown to have no significant effect on the metabolic profile and basal corticoids blood levels in adult offspring [25]. However, we cannot exclude a contribution of prenatal stress in the development of the phenotype of adult hypercortisolism. At PND 21, tissues were dissected from sacrificed mice from all experimental groups, and hormonal levels were evaluated. The rest of the animals were rehoused in post-weaning cages, placing two or three animals of the same experimental group in each cage to prevent isolation-induced stress. At PND 90, animals were sacrificed and tissues dissected and analyzed. The timing of experimental procedures is described in Table 1.

\section{Glycemia testing}

Since fasting during the lactation period could affect the model, only at the age of 90 PND, a part of the mice selected from each group has been submitted to the test for glycemia. In order to prevent a potential stress induced by fasting, plasma from these mice has not been used to analyze stress hormones. The collection of blood for all determinations, including glycemia, took place immediately after decapitation by gathering trunk blood. The test was performed in the morning, after 12-hour fasting, using test strips and a glucometer (One-Touch EuroFlash; Johnson \& Johnson Co). Each test was repeated twice, and the mean of the two measures was recorded.

\section{Plasma and tissue preparations}

Since mice have an inverted light/dark cycle compared to the humans' one, at 21 and 90 PND non-fasting animals have immediately been sacrificed between 09:00 and 12:00 in the noon, to identify hypercortisolism and classify also the ACTH status [26]. In order to avoid possible differences in stress procedures, the animals from one of the cages were picked up by three investigators at the time and gone through the experimental procedure at the same time.

Trunk blood was collected in either ice-chilled heparinized or in EDTA-containing tubes according to each hormone-specific assay protocol and spun at $3,500 \times g$ for 10 minutes at $4{ }^{\circ} \mathrm{C}$. Plasma was stored at $-80{ }^{\circ} \mathrm{C}$ until assayed. The total pituitary gland and the hypothalamus were dissected on dry ice and stored at $-80{ }^{\circ} \mathrm{C}$, following previously described procedures $[27,28]$. Before storing, pituitary glands of CTR and SM at 90 PND were weighted. On 
the day of assay, according to Spampinato and Goldstein [29], tissues were extracted in $0.1 \mathrm{mM}$ acetic acid at $90{ }^{\circ} \mathrm{C}$ and used throughout.

\section{Immune-reactive (ir-)ACTH, ir-CRH and ir-corticosterone determinations}

Tissue and plasma $i r$-CRH and $i r$-ACTH were measured with a double-antibody precipitation radioimmunoassay (RIA) [30]. The hACTH antibody (Dr. A.F. Parlow, Harbor-UCLA Medical Center, USA) fully recognizes mouse ACTH (139) and there is no significant cross-reactivity with other peptides derived from the proopiomelanocortin precursor [17]. In the same way, the mouse CRH antibody (Bachem AG, Bubendorf, Switzerland), shows no relevant cross-reactivity with other peptides derived from-CRH precursor [22]. The detection limit for $\mathrm{ACTH}$ was $6 \pm 0.23 \mathrm{pg} / \mathrm{ml}$; IC $\mathrm{IC}_{50}$ was $229 \pm 26 \mathrm{pg} / \mathrm{ml}$ (mean \pm S.D.); whereas CRH detection limit was $3 \pm 0.12 \mathrm{pg} / \mathrm{ml}$; $\mathrm{IC}_{50}$ was $14.7 \pm 1.5 \mathrm{pg} / \mathrm{ml}$ (mean \pm S.D.). $\left[{ }^{125} \mathrm{I}\right]$ iodotyrosyl2 $-\mathrm{ACTH}(1-39)\left[{ }^{125} \mathrm{I}\right]$ iodotyrosyl ${ }^{0}$-CRH were purchased from Amersham Biosciences (Milan, Italy) and Bachem AG (Bubendorf, Switzerland).

Ir-corticosterone-like material was assayed with RIA kits (ICN, Costa Mesa, CA, USA) as previously pointed out [31]. All assays were measured in duplicate and all determinations had intra-assay and inter-assay variations less than $2 \%$. Tissue proteins were measured as previously reported $[18,22,32,33]$.

\section{Statistics}

Results are presented as the mean \pm standard error $( \pm$ SE) of single animal data. Statistical analysis was performed using GraphPad Prism (version 7.05). All datasets were analyzed using the Brown-Forsythe test for normality. Datasets with normal distribution were analyzed for significance using one-way or two-way analysis of variance (ANOVA). Post hoc multiple comparisons were carried out using the Tukey's multiple comparisons or the Bonferroni post hoc test. Datasets with nonparametric distribution were analyzed using the Kruskal-Wallis test. Post hoc multiple comparisons were performed using the two-stage linear step-up procedure of Benjamini, Krieger, and Yekutieli. F-, H- and P values for individual statistical analyses, and post-hoc analyses, are reported in Table 2. A probability level of $\mathrm{P}<0,05$ was considered to be statistically significant.

\section{Results}

\section{Bodyweight and metabolic parameters}

Fig. 1 shows the pattern of body weight in CTR, SM, and AS male mice at different ages: from the end of the daily administered stress during the nursing period at 21 PND up to 90 PND. At 90 PND, SM showed a significant increment in total body weight compared to CTR and AS (Fig. 1A). In Fig. 1B, at 90 PND the post-hoc test shows that stress 
procedures triggered a consistent increase in fasting glycemia levels in adult age, while AS prevents completely stressinduced hyperglycemia.

\section{Hormonal parameters}

Stress hormones' expressions, recorded 30 minutes after (21 PND) and 70 days after the stressful period (90 PND) are reported for all experimental groups in Figure 2 and 3. At 21 PND in SM we observed an increase in the hypothalamic CRH and ACTH (hACTH) expression's level, considered archetype of all POMC derived peptides, respect to CTR (Fig. 2A and 2B, respectively), as well as an enhanced pituitary ACTH (pACTH) level (Fig. 3A) in SM vs the other groups. The SM also have circulating ACTH (cACTH) (Fig. 3B) and corticosterone (Fig. 3C) levels consistently higher than those of CTR and AS-treated mice.

After the unstressed period (90 PND), in hypothalamic dissected tissues from SM the CRH and hACTH levels were significantly lower and suppressed compared to that of the other groups (Fig. 2), whereas pACTH expression's level remains higher than in CTR and AS-treated mice (Fig. 3A). Both cACTH (Fig. 3B) and corticosterone levels (Fig. 3C) were higher in stressed animals than in CTR and AS-treated mice. The weights of fresh pituitary glands from SM were significantly higher than in control mice (Fig. 4).

\section{Discussion}

The present data confirm and extend the understanding of the pathogenic role of ES [19]. These results show that immediately after the stress procedures, CD-1 male mice present a transient rise of $\mathrm{CRH}$ expression, that decreases thereafter and appears to be suppressed at 90 PND. Simultaneously, we have observed a progressive increment of both pituitary and circulating $\mathrm{ACTH}$, as well as corticosterone plasma levels, which persisted from 21 up to $90 \mathrm{PND}$. These findings are accompanied by an increase in the total body weight curve, which becomes significantly higher after the unstressed period (from 21 to 90 PND). The treatment with AS-POMC prevents almost all the hormonal and metabolic alterations reported in SM, which may prevent not only pituitary ACTH secretion but also the activation of the CRH neurons during the stress phase [34]. Indeed, while measuring the hACTH, as an archetype of all POMC-derived peptides, we have detected different levels of this peptide in the experimental groups that are consistent with CRH trend. Since POMC (and ACTH itself) is the precursor of various MSH peptides able to act on melanocortin receptors [35,36], our data suggest a fundamental role of hypothalamic POMC positive neurons during stress, since the blunting of POMC expression by an AS can prevent the stress mediated CRH activation of the axis. Thereby, it is conceivable that, by acting on hypothalamic POMC neurons, the AS-POMC could have reduced the POMC-derived molecules, which are known to influence the responsiveness of hypothalamic neurons to stress. Furthermore, at 90 days, after being 
stressed in early-life, mice, but in the absence of active stress condition, could have developed an autonomous pituitary ACTH secretion. Indeed, the consequent high corticosterone circulating levels have been effective on the negative feedback only at the hypothalamic level, thus eventually decreasing CRH secretion (Fig. 5). Moreover, as a consequence of the prevention of $\mathrm{CRH}$ rise during the stress period, the treatment with AS-POMC is associated with normal expression levels of CRH and pituitary ACTH and, in consequence, of normal circulating parameters of HPA axis throughout the study period $[37,38]$.

The proposed pathogenic mechanism is in line with what have been published on the transgenic mouse model of CS, which is associated with stress-like neuroendocrine and autonomic changes and developing high corticosterone plasma levels and adrenal gland hypertrophy, due to an enduring hypothalamic CRH overexpression. In those studies, the basal plasma ACTH concentrations were not suppressed (as one would have expected in the presence of normal pituitary feedback due to GC excess), consistent with a partially autonomous ACTH hypersecretion [39]. Interestingly, the GC excess in our model appears clearly as ACTH-dependent because the hypothalamic CRH overexpression is restricted to the stress period during early-life, and is thereafter suppressed by the GC feedback. The increase in body weight as well as mild hyperglycemia, are also consistent with the development of a Cushing-like condition in the SM [40,41].

The whole body of these data suggests that a metabolic syndrome (overweight/hyperglycemia/hypertension) may originate from juvenile stress, which may induce a constant ACTH-dependent GC excess persisting even after the resolution of the stressful period of time. Furthermore, the possibility that stressful events in early-life could be associated with the occurrence of an ACTH autonomous secretion had already been proposed by other authors, who have observed that patients with a pituitary-dependent CS have had a relevant number of stressful events more in their youth rather than a normal control group [9]. On the other hand, the strict association of metabolic syndrome and GC excess, even of a mild degree, has been suggested by studies showing that a hidden hypercortisolism is more frequent than what was expected among patients with type 2 diabetes $[11,12,42,43]$. While we are aware that neuropsychological alterations are common in patients with clinically overt CS [44], in patients with less severe hypercortisolism data are scarce, but even the condition of subtle GC excess may influence patients' mental health and cognitive performance [45]. Moreover, recent studies imply that even in subjects without hypercortisolism, an increased degree of cortisol secretion (even though still within the normal range) is associated with the typical chronic complications of hypercortisolism (i.e. diabetes, hypertension, and osteoporosis) [46,47]. Therefore, it is conceivable that the stress condition, by increasing cortisol secretion, may lead to chronic consequences typical of CS [48].

Further studies are needed to identify other possible "actors" that could affect the proposed pathogenic mechanism, such as the arginine-vasopressin hormone (AVP), which is known to influence ACTH secretion. However, 
the clear effect of AS-POMC in normalizing the HPA axis alterations and the low AVP expression in paraventricular nucleus (PVN) CRH neurons, presented by other authors [9], suggests that CRH has the main role in mediating the ACTH hypersecretion in our model. Moreover, in the same way as our findings, it is reported a decrease in steady-state mRNA levels of CRH in the PVN of ES-experiencing pups, with an increase in corticosterone blood levels. By contrast, it was not observed a significant change in mRNA levels of arginine vasopressin in the hypothalamus of these mice [48]. In addition to the lack of AVP measurement, our study has other limitations. Firstly, we have not evaluated the changes in the GC receptor's expression that may influence different sensitivity in the negative feedback at the hypothalamic or pituitary level [49]. However, the consistency of the data obtained after POMC-AS administration suggests that the GC receptor's differences shall exert a minimal role in the pathogenesis of this persistent ACTH hypersecretion after stress in early-life. Secondly, we do still not know if the early stress is effectively associated with the development of corticotroph adenomas or with an increased function of the whole corticotroph population. The lack of a pituitary imaging and/or pituitary tissue investigation precludes us from solving this issue, however the observed increase in pituitary weight in SM (Fig. 4) prompts further studies on this model with histological analyses of pituitary tissue. Thirdly, in the hypothalamic tissue, we have not measured changes in POMC mRNA or POMC products other than ACTH in the adult mice following stress exposure.

Despite all these limitations, the HPA axis activity alterations of this mouse model may be consistent with the idea of an initial hypothalamic origin of the ACTH-secreting pituitary hyperplasia [50], which could promote corticotroph proliferation leading later on to an autonomous ACTH secretion.

In conclusion, these findings suggest that a chronic stress in early-life can induce a persistent up-regulation of the HPA axis generating endocrine, metabolic and somatic alterations very similar to those found in human ACTHdependent autonomous cortisol hypersecretion [13].

\section{Declaration}

\section{Funding}

This research did not receive any specific grant from any funding agency in the public, commercial or not-for-profit sector. The research activity of AF, LP and IC is partially supported by the Ricerca Corrente funds of IRCCS Istituto Auxologico Italiano (code: 05C921_2019).

\section{Conflicts of interest}

Authors declare that there is no conflict of interest that could be perceived as prejudicing the impartiality of the research reported. 


\section{Ethics approval}

All the procedures were carried out in accordance with the guidelines of the Council of European Communities

(European Communities Council Directive of 24 November 1986, 86/609/EEC) and following the approval of the

Bioethical Committee of the Italian National Institute of Health (Istituto Superiore di Sanità - ISS), and the Italian

Ministry of Health.

\section{Availability of data and material}

Data will be made available upon request.

\section{References}

1. J. K. Gjerstad, S. L. Lightman, and F. Spiga, Role of glucocorticoid negative feedback in the regulation of HPA axis pulsatility. Stress 21, 403 (2018).

2. E. T. Uchoa, G. Aguilera, J. P. Herman et al. Novel aspects of glucocorticoid actions. J. Neuroendocrinol. 26, 557 (2014).

3. N. C. Vamvakopoulos and G. P. Chrousos, Hormonal regulation of human corticotropin-releasing hormone gene expression: implications for the stress response and immune/inflammatory reaction. Endocr. Rev. 15, 409 (1994).

4. A. M. Bao and D. F. Swaab, The human hypothalamus in mood disorders: The HPA axis in the center. IBRO Reports 6, 45 (2019).

5. A. Chatzittofis, S. Arver, K. Öberg et al. HPA axis dysregulation in men with hypersexual disorder. Psychoneuroendocrinology 63, 247 (2016).

6. F. Xiong and L. Zhang, Role of the hypothalamic-pituitary-adrenal axis in developmental programming of health and disease. Front. Neuroendocrinol. 34, 27 (2013).

7. A. Agorastos, P. Pervanidou, G. P. Chrousos et al. Developmental Trajectories of Early Life Stress and Trauma: A Narrative Review on Neurobiological Aspects Beyond Stress System Dysregulation. Front. Psychiatry 10, 118 (2019).

8. O. Cooper, V. Bonert, F. Moser, et al. Altered Pituitary Gland Structure and Function in Posttraumatic Stress Disorder. J. Endocr. Soc. 1, 577 (2017).

9. N. Sonino, G. A. Fava, S. Grandi et al. Stressful life events in the pathogenesis of Cushing's syndrome. Clin. Endocrinol. (Oxf). 29, 617 (1988).

10. N. Sonino, G. A. Fava, and M. Boscaro. A role for life events in the pathogenesis of Cushing's disease. Clin. Endocrinol. (Oxf). 38, 261 (1993). 
11. B. Catargi, V. Rigalleau, A. Poussin et al. Occult Cushing's syndrome in type-2 diabetes. J. Clin. Endocrinol. Metab. 88,5808 (2003).

12. Chiodini, M. Torlontano, A. Scillitani et al. Association of subclinical hypercortisolism with type 2 diabetes mellitus: a case-control study in hospitalized patients. Eur. J. Endocrinol. 153, 837 (2005).

13. J. W. Findling and H. Raff, DIAGNOSIS OF ENDOCRINE DISEASE: Differentiation of pathologic/neoplastic hypercortisolism (Cushing's syndrome) from physiologic/non-neoplastic hypercortisolism (formerly known as pseudo-Cushing's syndrome). Eur. J. Endocrinol. 176, R205 (2017).

14. E. B. Geer, J. Islam, and C. Buettner. Mechanisms of glucocorticoid-induced insulin resistance: focus on adipose tissue function and lipid metabolism. Endocrinol. Metab. Clin. North Am. 43, 75 (2014).

15. H. Raff and T. Carroll, Cushing's syndrome: from physiological principles to diagnosis and clinical care. J. Physiol. 593, 493 (2015).

16. C. Steffensen, O. M. Dekkers, J. Lyhne et al. Hypercortisolism in Newly Diagnosed Type 2 Diabetes: A Prospective Study of 384 Newly Diagnosed Patients. Horm. Metab. Res. 51, 62 (2019).

17. A. Loizzo, S. Loizzo, G. Galietta, et al. Overweight and metabolic and hormonal parameter disruption are induced in adult male mice by manipulations during lactation period. Pediatr. Res. 59, 111 (2006).

18. S. Loizzo, G. Campana, S. Vella, et al. Post-natal stress-induced endocrine and metabolic alterations in mice at adulthood involve different pro-opiomelanocortin-derived peptides. Peptides 31, 2123 (2010).

19. A. Loizzo, S. M. Spampinato, G. Campana, et al. Etiopathogenesis and Pharmacological Prevention of a Type-2 Diabetes Model in Male Mice. J. Pharmacol. Exp. Ther. 364, 347 (2018).

20. N. C. Victoria and A. Z. Murphy, The long-term impact of early life pain on adult responses to anxiety and stress: Historical perspectives and empirical evidence. Exp. Neurol. 275, 261 (2016).

21. S. M. Mooney-Leber and S. Brummelte, Neonatal pain and reduced maternal care alter adult behavior and hypothalamic-pituitary-adrenal axis reactivity in a sex-specific manner. Dev. Psychobiol. 62, 631 (2019).

22. G. Galietta, A. Loizzo, S. Loizzo, et al. Administration of antisense oligonucleotide against pro-opiomelanocortin prevents enduring hormonal alterations induced by neonatal handling in male mice. Eur. J. Pharmacol. 550, 180 (2006).

23. A. Loizzo, S. M. Spampinato, A. Fortuna, et al. Antisense versus proopiomelanocortin mRNA reduces vascular risk in a murine model of type-2 diabetes following stress exposure in early post-natal life. Peptides 64, 34 (2015).

24. S. Spampinato, M. Canossa, L. Carboni, et al. Inhibition of proopiomelanocortin expression by an oligodeoxynucleotide complementary to beta-endorphin mRNA. Proc. Natl. Acad. Sci. U. S. A. 91, 8072 (1994). 
25. R. M. Philpot, M. E. Engberg, and L. Wecker, Effects of nicotine exposure on locomotor activity and pCREB levels in the ventral striatum of adolescent rats. Behav. Brain Res. 230, 62 (2012).

26. M. John, A. R. Lila, T. Bandgar, et al. Diagnostic efficacy of midnight cortisol and midnight ACTH in the diagnosis and localisation of Cushing's syndrome. Pituitary 13, 48 (2010).

27. S. C. Tzou, M. A. Landek-Salgado, H. Kimura, et al. Preparation of mouse pituitary immunogen for the induction of experimental autoimmune hypophysitis. J. Vis. Exp. 46, 2182 (2010).

28. M. K. Gill, S. Karanth, A. Dutt, et al. Effect of castration and steroid treatment on the release of gonadotropins by the rat pituitary-hypothalamus complex in vitro. Horm. Metab. Res. 17, 141 (1985).

29. S. Spampinato and A. Goldstein, Immunoreactive dynorphin in rat tissues and plasma. Neuropeptides 3, 193 (1983).

30. W. E. Nicholson, D. R. Davis, B. J. Sherrell, et al. Rapid radioimmunoassay for corticotropin in unextracted human plasma. Clin. Chem. 30, 259 (1984).

31. F. Fontana, P. Bernardi, E. M. Pich, et al. Opioid peptide modulation of circulatory and endocrine response to mental stress in humans. Peptides 18, 169 (1997).

32. M. M. Bradford, Anal. Biochem. A rapid and sensitive method for the quantitation of microgram quantities of protein utilizing the principle of protein-dye binding. 72, 248 (1976).

33. S. Loizzo, S. Vella, A. Loizzo, et al. Sexual dimorphic evolution of metabolic programming in non-genetic nonalimentary mild metabolic syndrome model in mice depends on feed-back mechanisms integrity for proopiomelanocortin-derived endogenous substances. Peptides 31, 1598 (2010).

34. V. Mela, F. Díaz, M. J. Vázquez, et al. Interaction between neonatal maternal deprivation and serum leptin levels on metabolism, pubertal development, and sexual behavior in male and female rats. Biol. Sex Differ. 7, 2 (2016).

35. R. M. Dores, Adrenocorticotropic hormone, melanocyte-stimulating hormone, and the melanocortin receptors: Revisiting the work of robert schwyzer: A thirty-year retrospective. in Ann. N. Y. Acad. Sci. (Blackwell Publishing Inc., 2009), pp. 93-100.

36. R. D. Cone, Studies on the physiological functions of the melanocortin system. Endocr. Rev. 27, 736 (2006).

37. J. P. Herman and J. G. Tasker, Paraventricular Hypothalamic Mechanisms of Chronic Stress Adaptation. Front. Endocrinol. (Lausanne). 7, 137 (2016).

38. C. J. Rice, C. A. Sandman, M. R. Lenjavi, et al. A novel mouse model for acute and long-lasting consequences of early life stress. Endocrinology 149, 4892 (2008).

39. L. Groenink, A. Dirks, P. M. Verdouw, et al. HPA axis dysregulation in mice overexpressing corticotropin releasing hormone. Biol. Psychiatry 51, 875 (2002). 
40. M. J. Lee, P. Pramyothin, K. Karastergiou, et al. Deconstructing the roles of glucocorticoids in adipose tissue biology and the development of central obesity. Biochim. Biophys. Acta 1842, 473 (2014).

41. C. Scaroni, M. Zilio, M. Foti, et al. Glucose Metabolism Abnormalities in Cushing Syndrome: From Molecular Basis to Clinical Management. Endocr. Rev. 38, 189 (2017).

42. L. C. Martins, F. L. Conceição, E. S. Muxfeldt, et al. Prevalence and associated factors of subclinical hypercortisolism in patients with resistant hypertension. J. Hypertens. 30, 967 (2012).

43. M. Terzolo, G. Reimondo, I. Chiodini, et al. Screening of Cushing's syndrome in outpatients with type 2 diabetes: results of a prospective multicentric study in Italy. Clin. Endocrinol. Metab. 97, 3467 (2012).

44. R. Pivonello, A. M. Isidori, M. C. De Martino, et al. Complications of Cushing's syndrome: state of the art. Lancet Diabetes Endocrinol. 4, 611 (2016).

45. V. Morelli, C. Aresta, A. Gaudio et al. Prediction of hypertension, diabetes and fractures in eucortisolemic women by measuring parameters of cortisol milieu. Endocrine 68, 411 (2020).

46. V. Morelli, A. Ghielmetti, A. Caldiroli et al. Mental health in patients with adrenal incidentalomas: is there a relation with different degrees of cortisol secretion? J Clin Endocrinol Metab. dgaa695 (2020).

47. V. Morelli, C. Aresta, A. Gaudio et al. Prediction of hypertension, diabetes and fractures in eucortisolemic women by measuring parameters of cortisol milieu. Endocrine 68, 411 (2020).

48. G. Tirabassi, M. Boscaro, and G. Arnaldi, Harmful effects of functional hypercortisolism: a working hypothesis. Endocrine 46, 370 (2014).

49. V. Morelli, F. Donadio, C. Eller-Vainicher, et al. Role of glucocorticoid receptor polymorphism in adrenal incidentalomas. Eur. J. Clin. Invest. 40, 803 (2010).

50. R. N. Clayton and W. E. Farrell, Pituitary tumour clonality revisited. Front. Horm. Res. 32, 186 (2004).

\section{Figure legends}

\section{Table 1}

\section{Stress procedures' timing.}

Table 2

\section{Statistical analysis.}

\section{Figure 1}

Metabolic parameters. Total body weight (A) and fasting glycemia (B). (A) Total body weights at 21 ( $n=8$ per group), 30 ( $n=6$ per group), 60 ( $n=12$ per group), and 90 ( $n=12$ per group) days of age in the three groups of mice. CTR indicates the undisturbed mice group; SM indicates mice underwent stress procedures; AS indicates SM treated with 
antisense-POMC. Statistical analyses were performed using ANOVA and analyzed using the Bonferroni post hoc test, (B) fasting glycemia ( $n=6$ per group) were performed using ANOVA followed by the Tukey's multiple comparisons test. Values are expressed as mean $\pm \mathrm{SE} . * \mathrm{P}<0.05 ; * * * \mathrm{P}<0.001$ for $\mathrm{CTR}$ vs $\mathrm{SM} .{ }^{\S} \mathrm{P}<0.01$ for $\mathrm{SM}$ vs AS.

\section{Figure 2}

Hypothalamic parameters. Immunoreactive content of hypothalamic ACTH (hACTH) (A) or CRH (B) of mice at 21 PND ( $n=6-7$ per group) and 90 PND ( $n=5$ per group). Values are expressed as mean \pm SE. Statistical analysis was performed depending on the distribution parametricity of data. Datasets with normal distribution were analyzed for significance using a one-way analysis of variance or two-way (ANOVA). Post hoc multiple comparisons were carried out using the Tukey's multiple comparisons or the Bonferroni's post hoc test. Datasets with nonparametric distribution were analyzed using the Kruskal-Wallis test. Post hoc multiple comparisons were carried out using the two-stage linear step-up procedure of Benjamini, Krieger and Yekutieli, ${ }^{*} \mathrm{P}<0.05$; $* * * \mathrm{P}<0.001$ for $\mathrm{CTR}$ vs other groups. ${ }^{\S} \mathrm{P}<0.05$, $\S \S \mathrm{P}<0.001$ for $\mathrm{SM}$ vs AS.

\section{Figure 3}

Pituitary and plasmatic parameters. Pituitary content of pACTH (A) and circulating cACTH (B) and corticosterone (C) of mice at 21 PND ( $n=6-7$ per group) and 90 PND ( $n=5$ per group). Values are expressed as mean \pm SE. Statistical analysis was performed depending on the distribution parametricity of data. Datasets with normal distribution were analyzed for significance using a one-way analysis of variance (ANOVA). Post hoc multiple comparisons were carried out using the Tukey's multiple comparisons test. Datasets with nonparametric distribution were analyzed using the Kruskal-Wallis test. Post hoc multiple comparisons were carried out using the two-stage linear step-up procedure of Benjamini, Krieger and Yekutieli, $* * * \mathrm{P}<0.001$ for CTR vs SM. ${ }^{\S} \mathrm{P}<0.01$ for SM vs AS.

\section{Figure 4}

\section{Pituitary weights.}

Weights of fresh pituitary glands of control and stressed mice at 90 PND ( $n=5$ per group). Values are expressed as mean \pm SE. Statistical analysis was performed depending on the distribution parametricity of data. Datasets were analyzed for significance using an unpaired t-test, $* \mathrm{P}<0.05$ for CTR vs SM.

\section{Figure 5}

Summary scheme. Our data are consistent with an autonomous corticotropin secretion in 90 PND mice undergoing a stressful treatment in early life. 
A

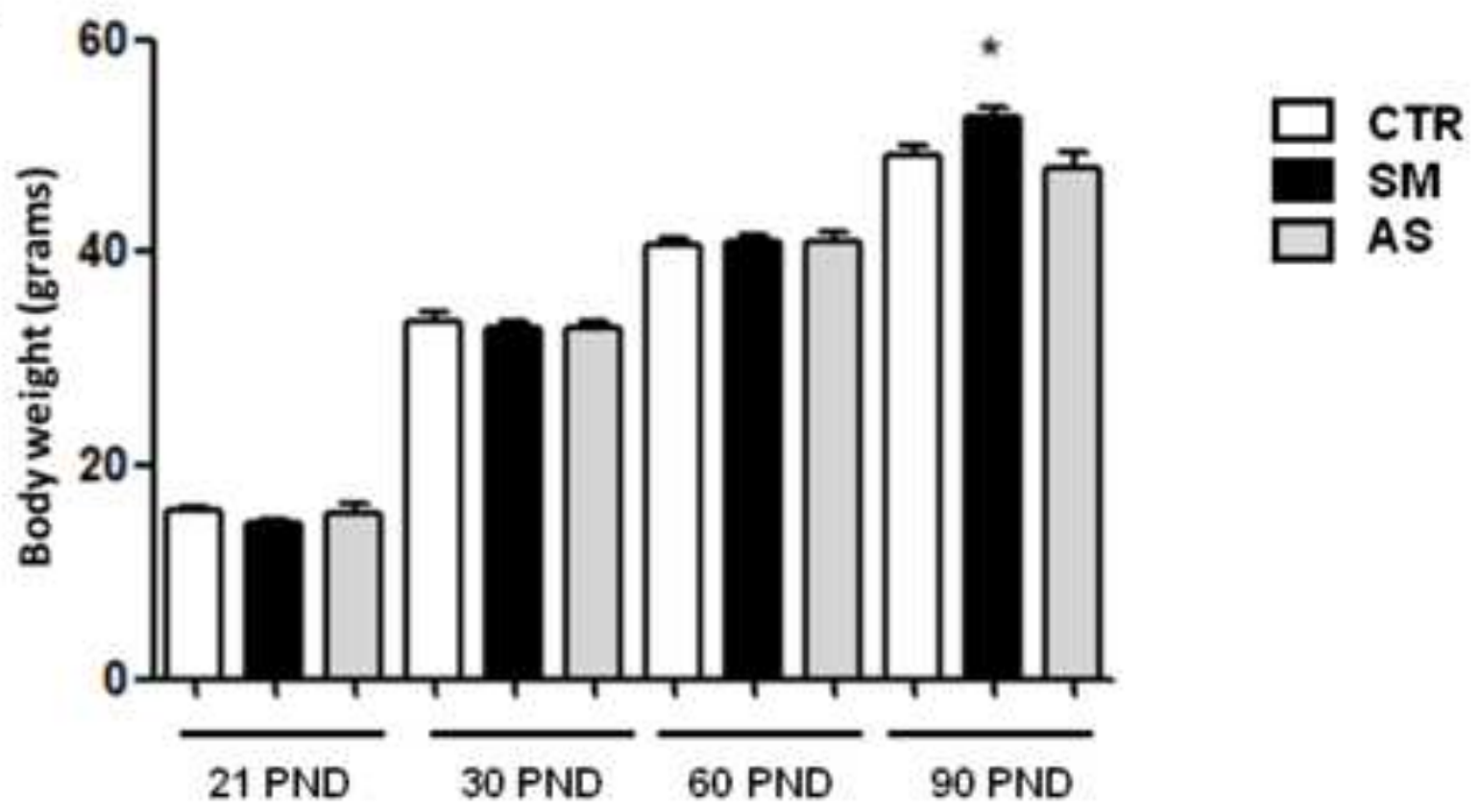

B

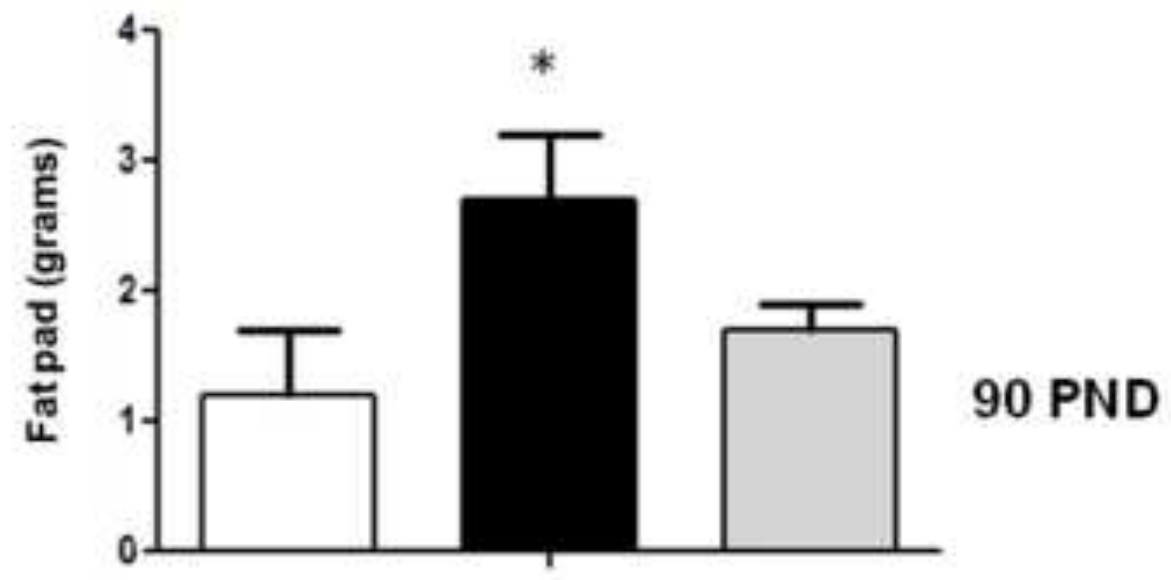

C

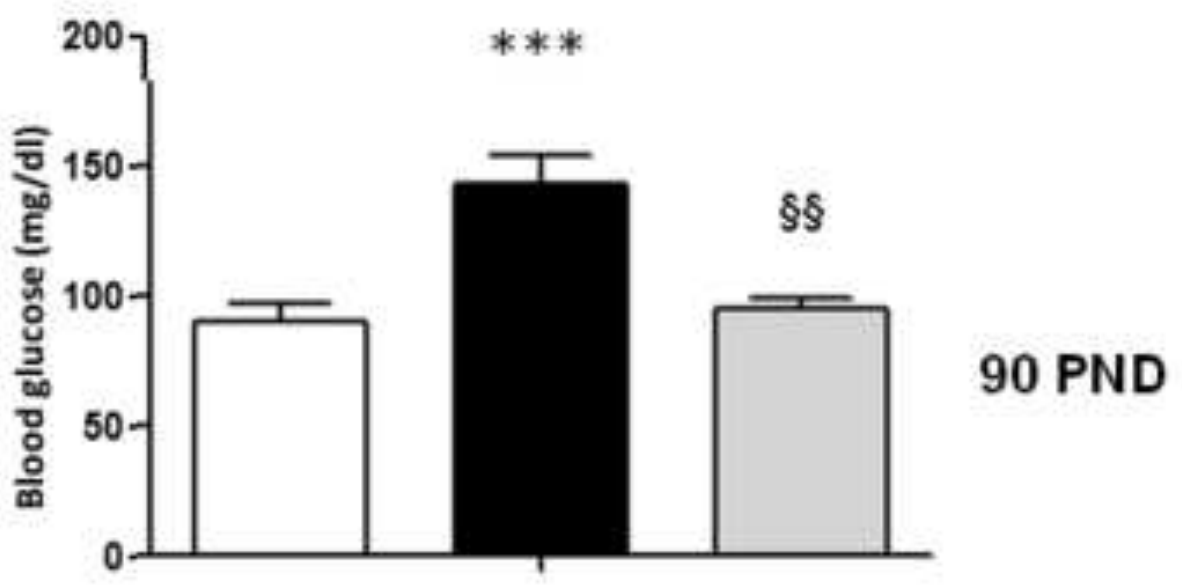

Fig 1 


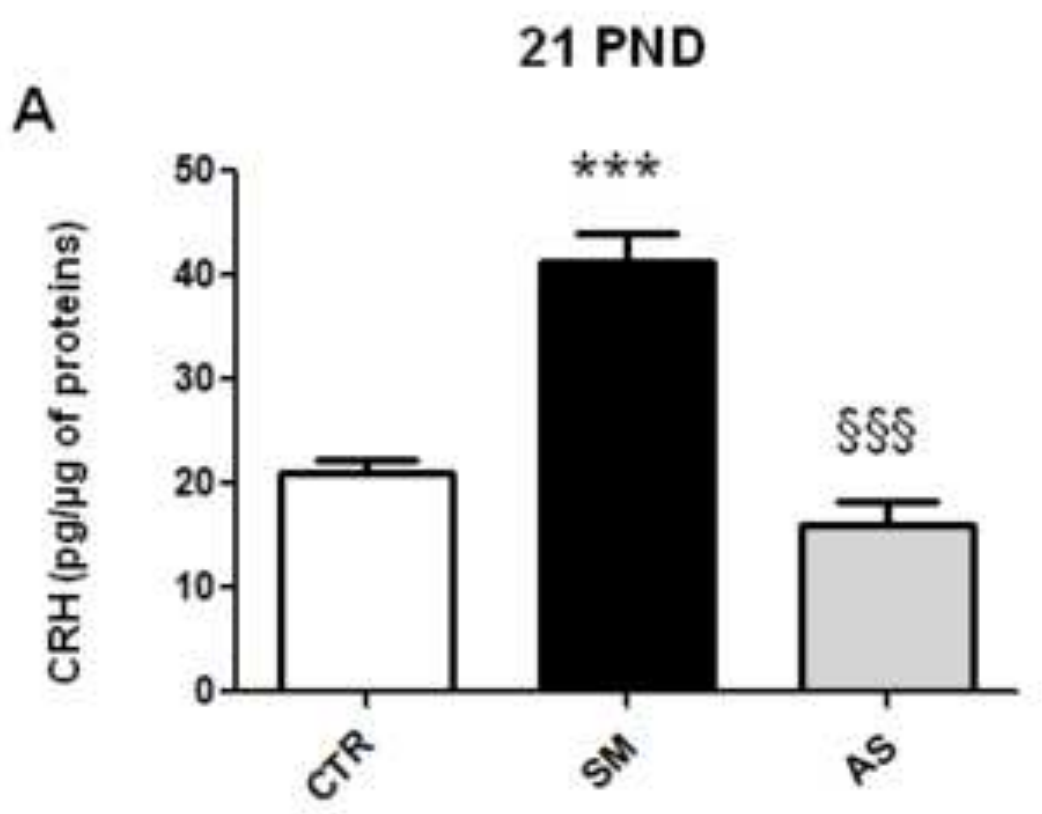

B

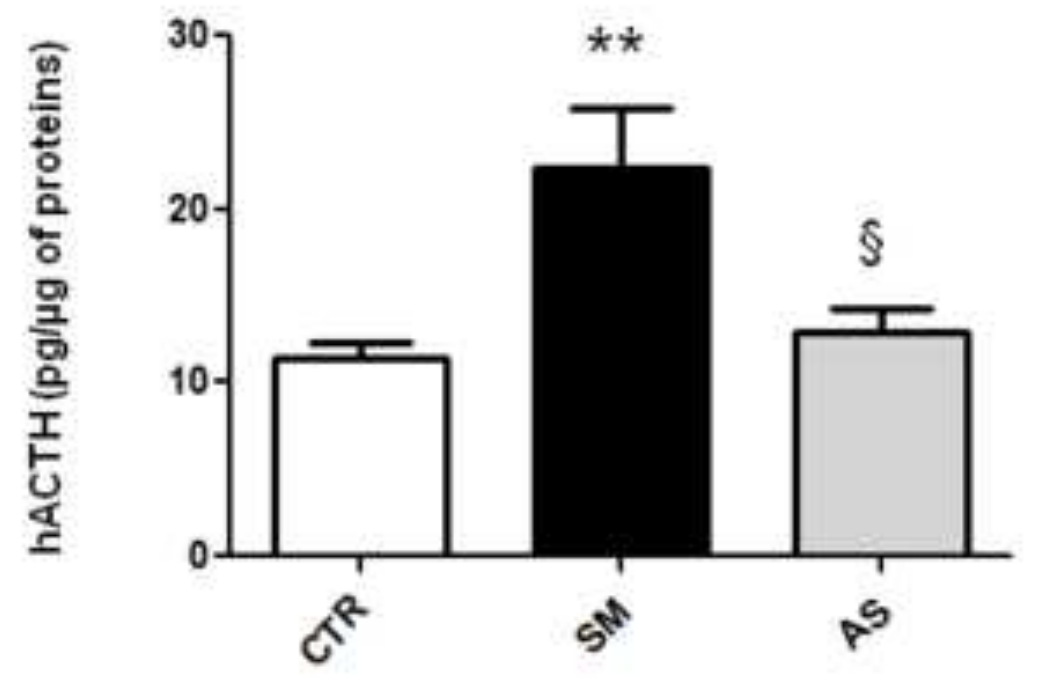

Fig 2
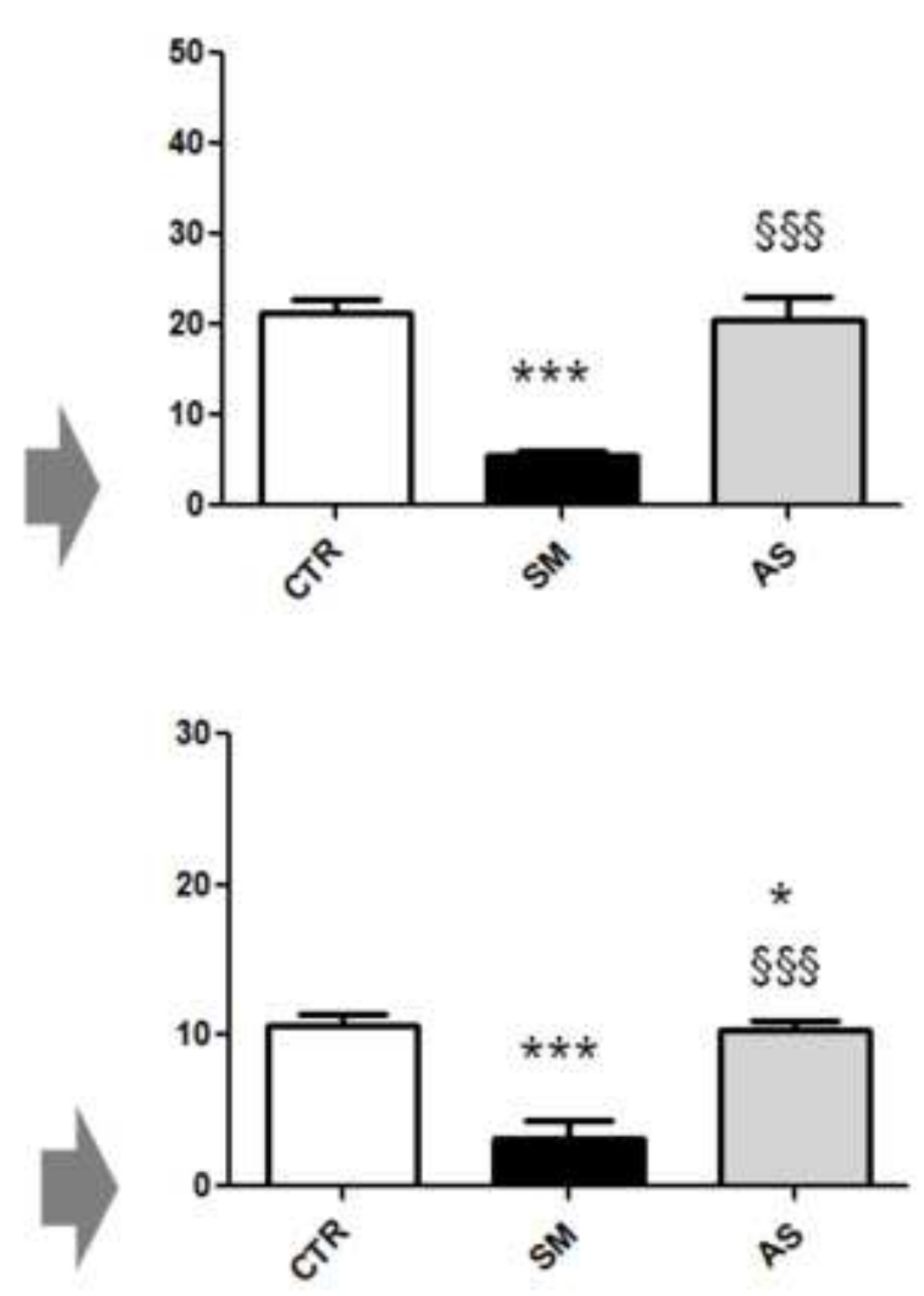

90 PND 


\section{PND}

A

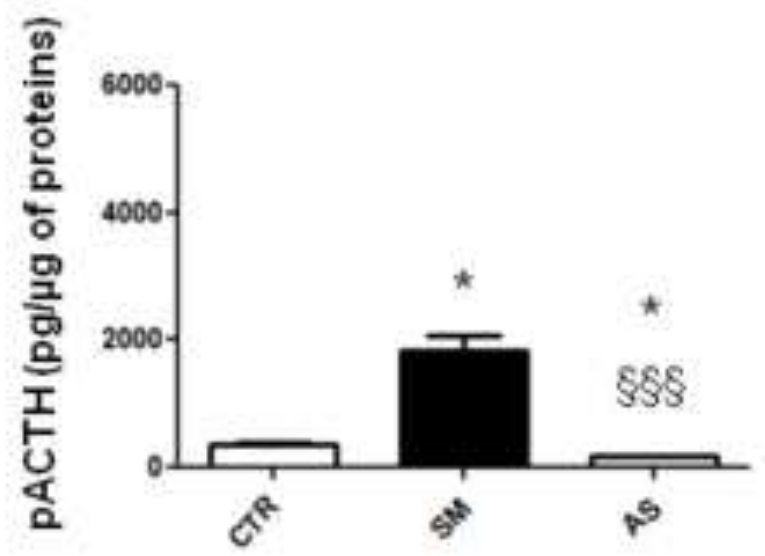

B

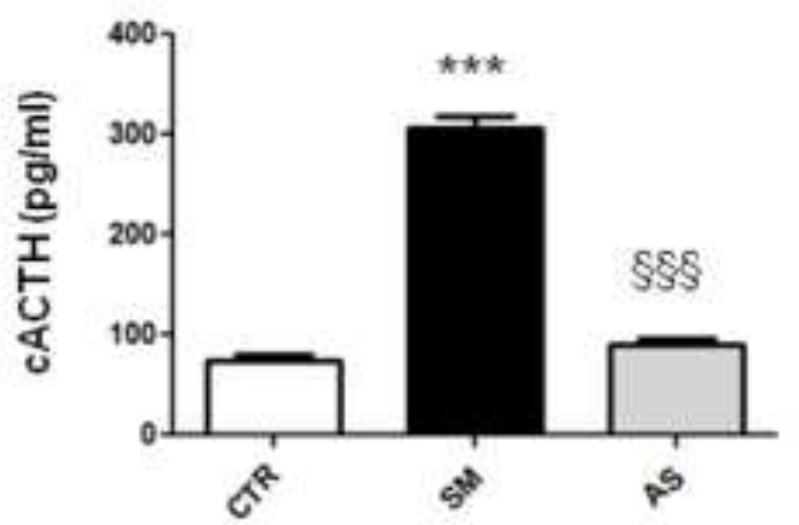

C

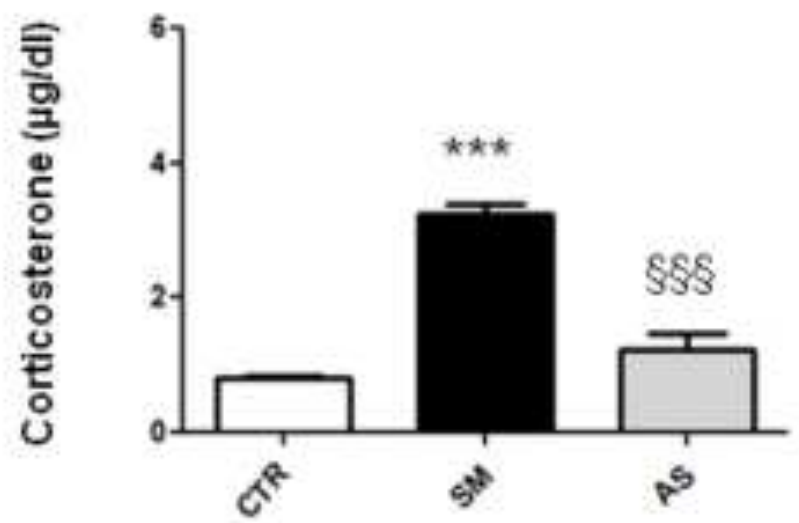

90 PND
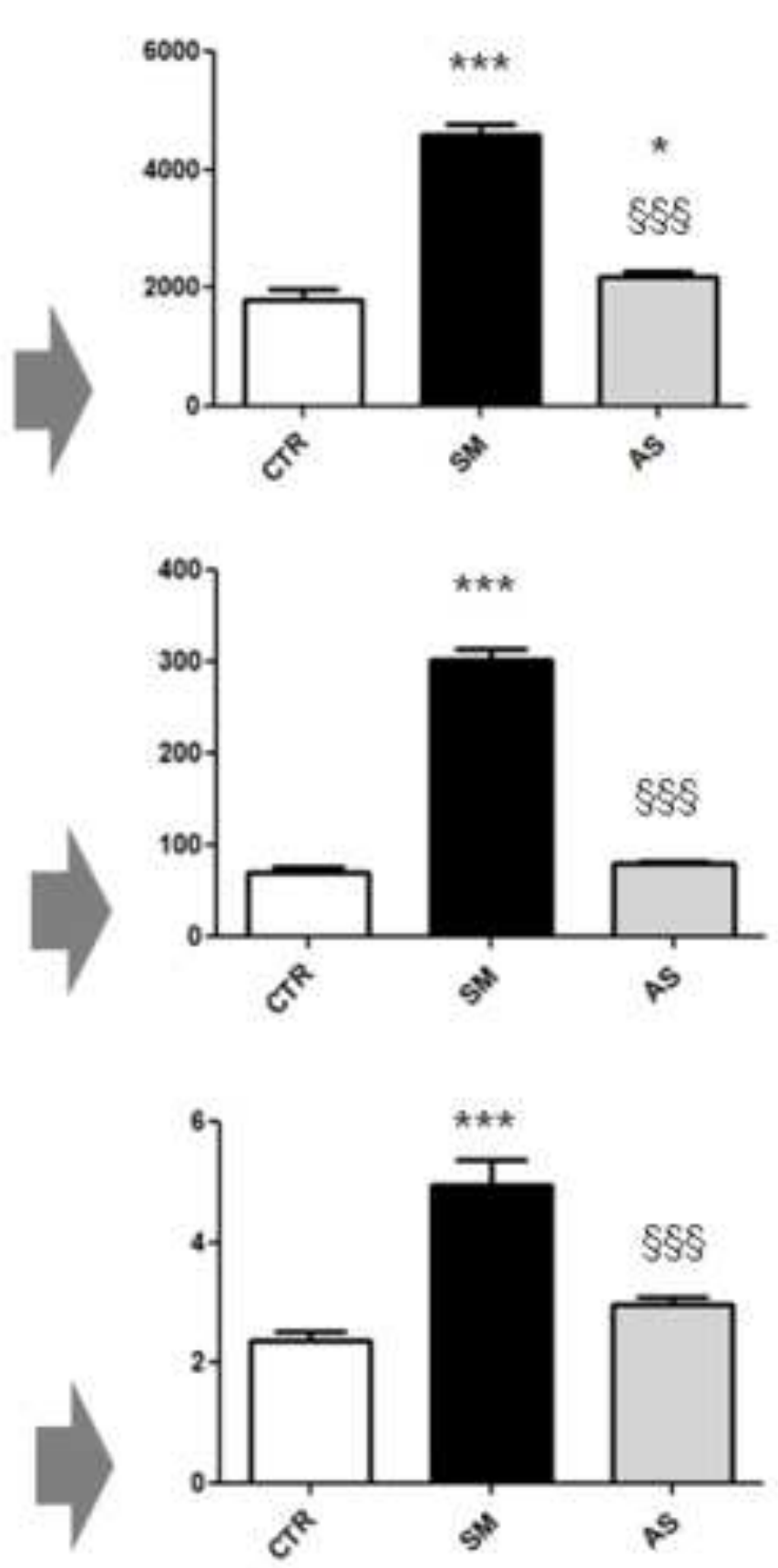

Fig 3 
(50 PND

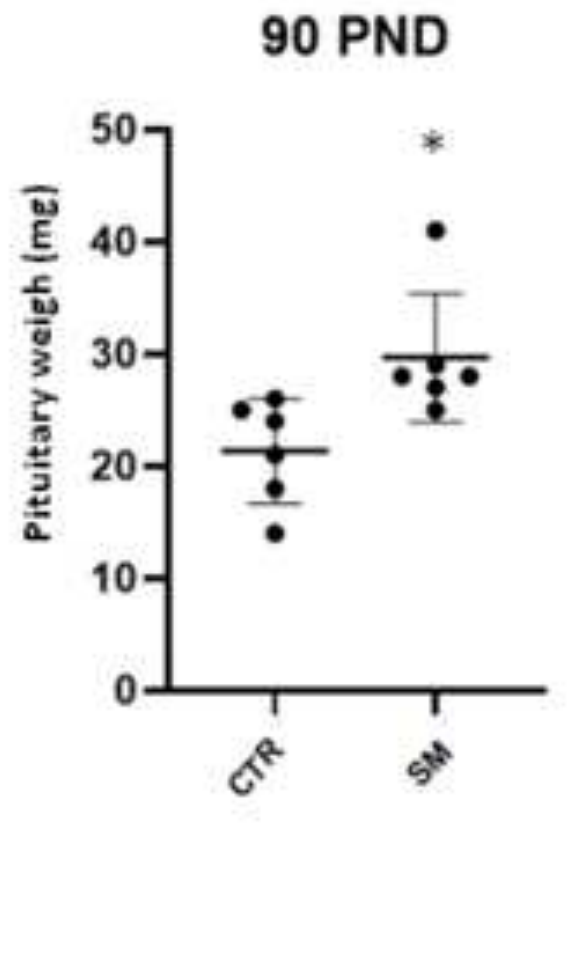

Fig 4

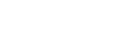

(1)

(1)

$x^{2}$

Click here to access/download;Figure;Fig 4.tif $\bullet$

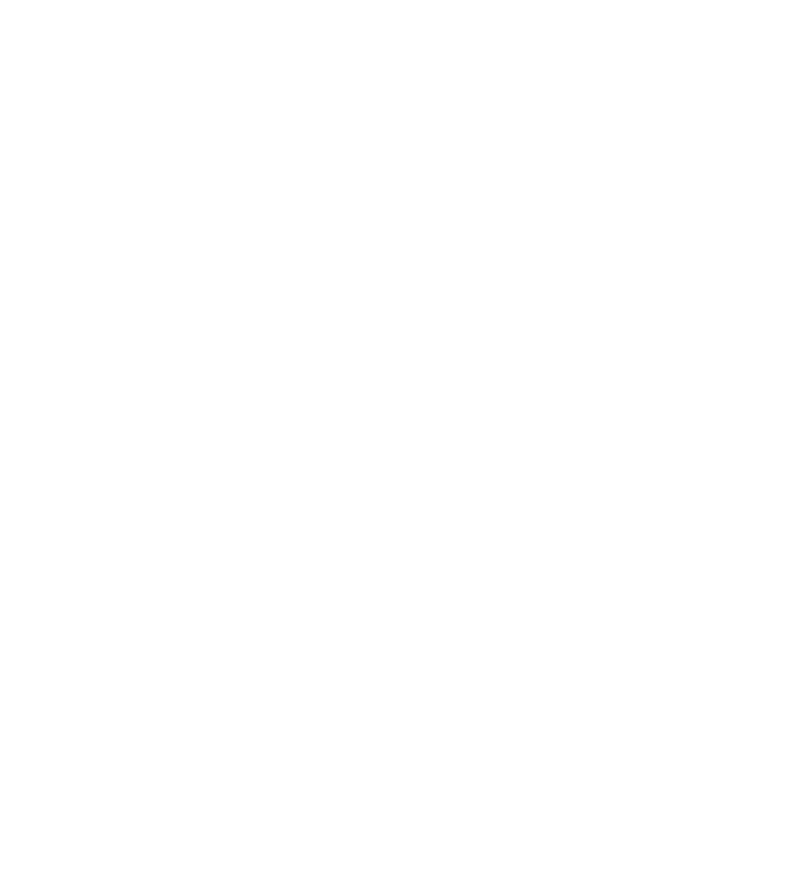

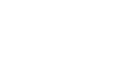



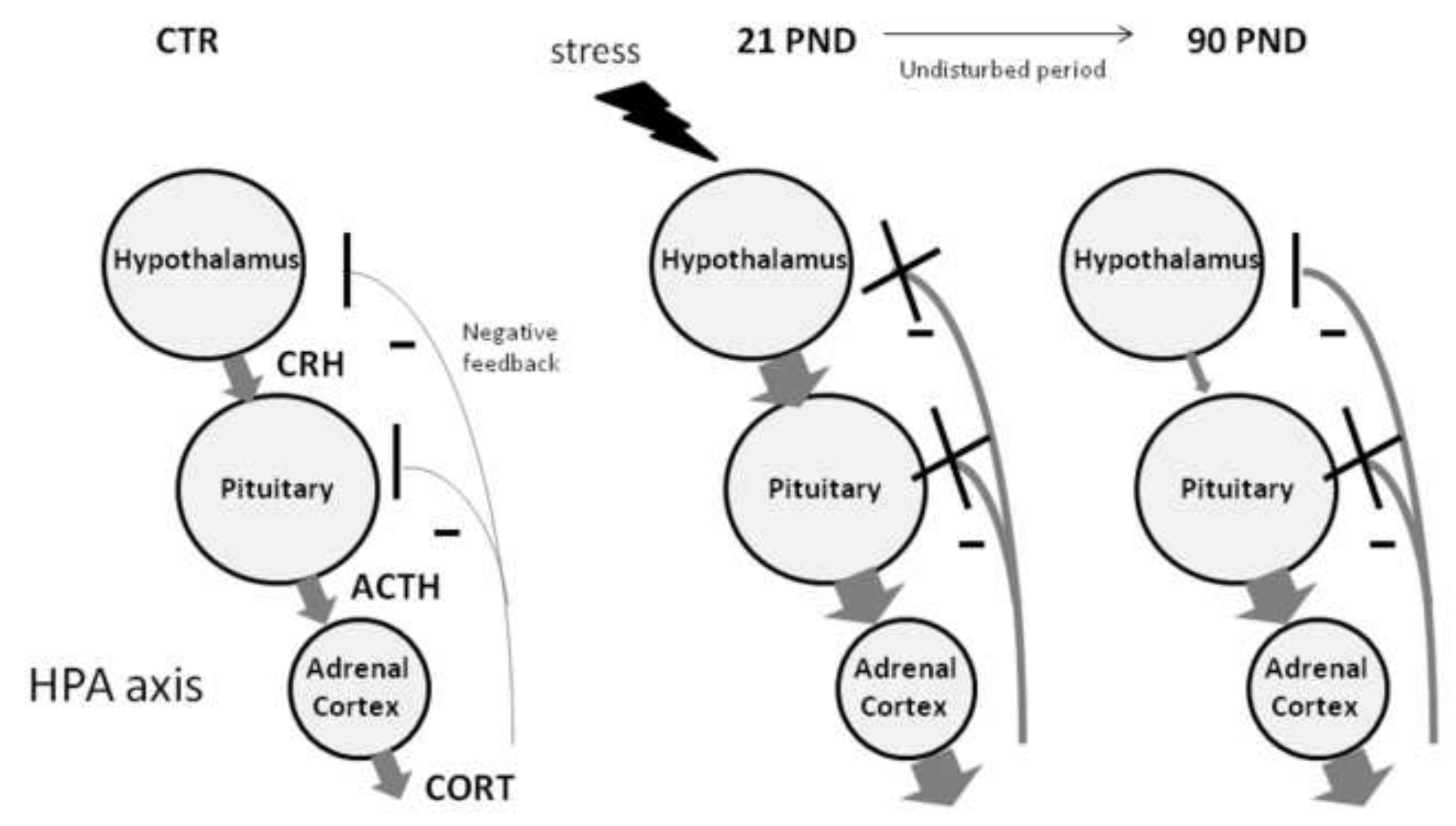

Fig 5 


\begin{tabular}{|c|l|}
\hline Age & \multicolumn{1}{|c|}{ Experimental procedures } \\
\hline Day-7 & Pregnant mother are transferred in our Lab \\
\hline Day1 & Day of the birth \\
\hline Day 2 & Starting of post-natal stress procedures \\
\hline Day 21 & $\begin{array}{l}\text { Ending of post-natal stress procedures. Then, } \\
\text { animals are left undisturbed }\end{array}$ \\
\hline Day90 & Pathological phenotype \\
\hline
\end{tabular}

Tab 1 


\begin{tabular}{|c|c|c|c|c|}
\hline Data & Figure: & $\begin{array}{l}\text { Normal distribution } \\
\text { (Param etricity) }\end{array}$ & $\begin{array}{l}\text { Statistical Analysis (Overall } \\
\text { Effects) }\end{array}$ & Post Hoc analysis \\
\hline Bodfy weight & $\operatorname{Fog} 1 \mathrm{~A}$ & $\begin{array}{l}\text { Yes } \\
\text { Erown Forsythe sest F }(11,96) \\
=1.798, p=0,062 .\end{array}$ & 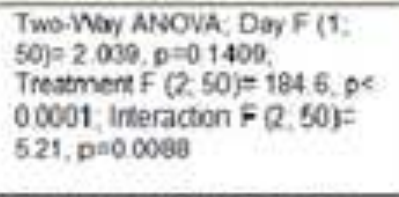 & 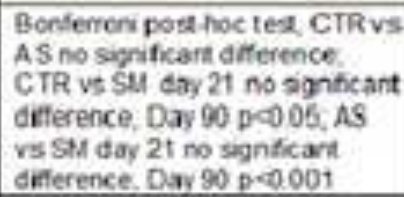 \\
\hline $\begin{array}{l}\text { Fasing } \\
\text { Glycema. }\end{array}$ & $\mathrm{Fg} 18$ & $\begin{array}{l}\text { Yes } \\
\text { Erown Fonsy the test } F(2,15) \\
=2362, p=0,1283\end{array}$ & $\begin{array}{l}\text { One.Way ANOVA. } F(2,15)= \\
14: 11, p=0.0004\end{array}$ & $\begin{array}{l}\text { Tukey's mullipie cocrpansons } \\
\text { test CTRvs SM } p=0 \text { 0007. } \\
\text { CTR vs. AS } p=0.91 \text {. SU vs AS } \\
p=00015\end{array}$ \\
\hline CES 21 PWD & $\mathrm{Fo} 2 A$ & $\begin{array}{l}\text { Yes } \\
\text { Brown-Forsythe test } F(2,16) \\
=2.6, p=05418\end{array}$ & $\begin{array}{l}\text { One.Way ANOVA } F(2,16)= \\
37.62, p=00001\end{array}$ & 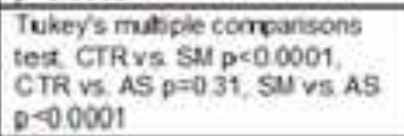 \\
\hline CFA 90 PND & $\mathrm{Fig} 2 \mathrm{~A}$ & $\begin{array}{l}\text { Yes } \\
\text { Brown Forsythe wst } F(2,12) \\
=1,399, p=0,2843\end{array}$ & $\begin{array}{l}\text { One-Wxy ANOVIA F } Q, 12)= \\
2841, p<0.0001\end{array}$ & 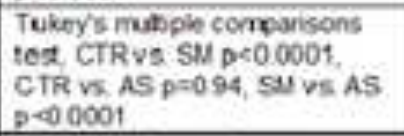 \\
\hline $\begin{array}{l}\text { haOTH } 21 \\
\text { PNO }\end{array}$ & Fig 23 & $\begin{array}{l}\text { No } \\
\text { Brown Forsy the fest } F(2,15) \\
=5,263 ; p=0.0188\end{array}$ & $\begin{array}{l}\text { Krukal-Walis ies, } \mathrm{HE} \text { 1096, D } \\
\text { (ead) }=0,0006\end{array}$ & 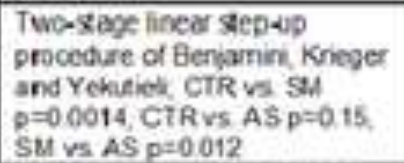 \\
\hline $\begin{array}{l}\text { WACTH } 90 \\
\text { PND. }\end{array}$ & $\mathrm{Fg} 28$ & $\begin{array}{l}\text { Yes } \\
\text { Erown-Forsythe sest } F(2,12) \\
=2,6, p=0.1153\end{array}$ & $\begin{array}{l}\text { Cne-Way ANCVA, F }(2,12)= \\
\text { t0 } 52,000,0001\end{array}$ & $\begin{array}{l}\text { Tukey's mutiple compansons } \\
\text { test CTRva SM p<0.0001 } \\
\text { CTR vs. AS pic0 05, SU vs AS } \\
\text { D=0.0002 }\end{array}$ \\
\hline $\begin{array}{l}\text { PACTH } 21 \\
\text { PND }\end{array}$ & $\mathrm{Fog}$. $\mathrm{A}$ & $\begin{array}{l}\text { No } \\
\text { Brown-Forsythe west } F(2,16) \\
=4.685, p=0.025\end{array}$ & $\begin{array}{l}\text { Kruskal-Walls test, he } 16.0 \text { t, p } \\
\text { (exact) }<0.0001\end{array}$ & 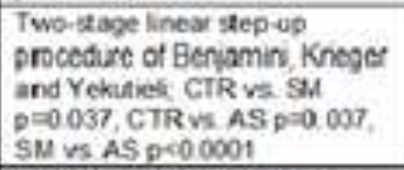 \\
\hline $\begin{array}{l}\text { PACTH 90 } \\
\text { PND }\end{array}$ & $\mathrm{Fog} 3 \mathrm{~A}$ & $\begin{array}{l}\text { Yes } \\
\text { Brown Forgythe ust } F(2,12) \\
=2,6, p=0.1153\end{array}$ & $\begin{array}{l}\text { One Way ANCVA F }(2,12)= \\
42.52,960.001\end{array}$ & 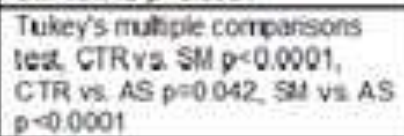 \\
\hline $\begin{array}{l}\text { OACTH } 21 \\
\text { PNO }\end{array}$ & $\mathrm{Fag} 38$ & $\begin{array}{l}\text { Yes } \\
\text { Brown Forsythe lest } F \cdot(2,12) \\
=1.537, p=0.264\end{array}$ & $\begin{array}{l}\text { One.Way ANOVA, F (2, 12)" } \\
356.9,000.0001\end{array}$ & 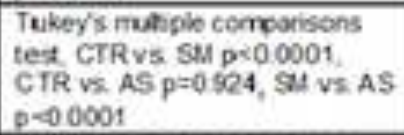 \\
\hline $\begin{array}{l}\text { CACIH } 90 \\
\text { PNO }\end{array}$ & $\mathrm{Fig} 38$ & $\begin{array}{l}\text { Yes } \\
\text { Erown Foroy the test } F(2,12) \\
=1.496, p=0.263\end{array}$ & $\begin{array}{l}\text { Che-Way ANOVA- F Q }, 12)= \\
218.2, p<0.0001\end{array}$ & 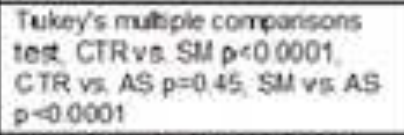 \\
\hline $\begin{array}{l}\text { CORT } 21 \\
\text { PND }\end{array}$ & Fon $3 \mathrm{C}$ & $\begin{array}{l}\text { Yes } \\
\text { Brown Forsy the test } F(2,12) \\
=2,478, p=0,125\end{array}$ & $\begin{array}{l}\text { One-Wwy ANOVA } F Q, 12)= \\
6633, p=00001\end{array}$ & $\begin{array}{l}\text { Tekey's mitiple compansons } \\
\text { tes, CTRvs. SM p<0 0001, } \\
\text { CTR vs. AS } p=02077, \$ 2 \text { vs AS } \\
p=0.0004\end{array}$ \\
\hline $\begin{array}{l}\text { CORT 90 } \\
\text { PND }\end{array}$ & $\mathrm{Fg} 3 \mathrm{C}$ & $\begin{array}{l}\text { Yes } \\
\text { Erown. Forsy the test } F(2,12) \\
=2.732, p=0.1063\end{array}$ & $\begin{array}{l}\text { One.Way ANONA F }(2,12)= \\
27.77,900.0001\end{array}$ & $\begin{array}{l}\text { Tukey's mult ple comparisons } \\
\text { test. CTRvs SM pe0 } 0001 \text {. } \\
\text { CTR vs. AS pe0 } 25 \text {, SU vs AS } \\
\rho=0.0004\end{array}$ \\
\hline $\begin{array}{l}\text { PITUTARYY } \\
\text { WEIGAT } 90 \\
\text { PNO }\end{array}$ & $\mathrm{Fig} 4$ & $\begin{array}{l}\text { Yes F ted for unequal } \\
\text { variance }(4,4)=1.754 \text {; } \\
\text { p } 00.5804\end{array}$ & $\begin{array}{l}\text { Unpared tres, } \mathrm{r}=2,652, \mathrm{~d}=8, \\
p=0,0291\end{array}$ & \\
\hline
\end{tabular}

